\title{
LA INICIATIVA LEGISLATIVA POPULAR EN ESPAÑA*
}

FRANCISCO ASTARLOA VILLENA

Profesor Titular de Derecho Constitucional

Universidad de Valencia

\author{
"Vientos del pueblo me llevan, \\ vientos del pueblo me arrastran, \\ me esparcen el corazón \\ y me aventan la garganta. \\ (Miguel Hernández, \\ "Viento del pueblo", 1937)
}

\section{INTRODUCCIÓN}

El Texto Constitucional español de 1978 ha sido objeto de estudio desde muchos puntos de vista, no sólo en su aspecto global, sino también en buena parte de su contenido parcial. Muchas razones, que no son del caso recordar aquí y ahora, han fundamentado el interés que esa Constitución ha despertado entre la doctrina, tanto nacional como extranjera.

Sin embargo, y como es lógico, no toda la Constitución ha despertado un interés igual. Muy posiblemente los temas relacionados con la regulación de los derechos y las libertades y el estudio de algunas instituciones, como por ejemplo, el Tribunal Constitucional, han sido, junto a todo lo relacionado con el Estado autonómico, los aspectos del Texto Constitucional que han suscitado ese interés mayor, y, por tanto, una mayor profundización doctrinal.

Por contra, las manifestaciones de democracia directa apenas han llamado la atención de la doctrina del Derecho Constitucional, exceptuando algunos casos aislados. No es de extrañar, por el escaso relieve que la Constitu-

* Algunos aspectos de este artículo aparecen también recogidos en J.Oliver, Política y Derecho, Universitat de les Illes Balears-Tirant lo Blanch, Valencia, 1996. 
ción concede a dichas manifestaciones, siguiendo, por lo demás, criterio generalizado internacionalmente.

Se afronta la realización de este trabajo con ese relativo entusiasmo que produce bucear en aquello que es poco conocido. Pretende realizar una cierta profundización acerca de una manifestación de la democracia directa -eso es la iniciativa legislativa popular- y ayudar a entender cuál ha sido y es su tratamiento en España y cuál la clave del retraimiento provocado.

Este estudio de la iniciativa legislativa popular en España se realiza aquí discurriendo de lo genérico a lo específico, o sea, partiendo de la democracia como caracterizadora del Estado actual y de los modos de ejercerla, o sea, la democracia directa y la democracia representativa. A continuación se examinan las distintas opciones de la democracia directa, para situar luego una de esas opciones -la iniciativa legislativa popular-como aspecto central de este estudio.

Dicho objetivo es abordado, en primer lugar, desde el conflictivo aspecto de su naturaleza jurídica, para analizar, a continuación, la titularidad de la iniciativa, su objeto -con referencia a las materias excluidas del mismo- los requisitos para ejercerla y el procedimiento para llevarla a la práctica.

\section{DEMOCRACIA DIRECTA Y DEMOCRACIA REPRESENTATIVA}

Las dos grandes manifestaciones del ejercicio del derecho de participación -la democracia directa y la democracia representativa- han tenido, desde el comienzo mismo del liberalismo, sus defensores y sus detractores.

El profesor Luis Aguiar de Luque define la democracia directa como "aquel régimen político en que la adopción de decisiones de interés general para la comunidad corresponde a la totalidad de los ciudadanos, que se pronuncian respecto a ellas de modo personal e individualizado" ${ }^{~}$.

El gran defensor de la democracia directa fue, sin duda, Juan Jacobo Rousseau. Opinaba que la voluntad general es inalienable, por lo que no puede ser representada. Por ello, la formación de la voluntad general requiere la participación directa de todos los ciudadanos, sin la mediación de los representantes.

Por el contrario, Condorcet - pese a que pensaba que la democracia directa era más deseable en teoría-, y, sobre todo, Sièyes y Montesquieu, defenderán la ventaja del sistema representativo, por el que el pueblo soberano, incapaz de tomar decisiones políticas, queda sustituido por minorías representantes, que, previa elección por el mismo pueblo, actúan en su nombre.

El proceso histórico que nace con la Revolución francesa ha ido decantando la balanza en favor de la democracia representativa. Y ello ha sido así, hasta el punto de que la democracia directa, nacida en la doctrina misma de esa Revolución, ha ido transitando a gran velocidad hasta las posiciones más

1. Aguiar de LuQue, Luis: Democracia directa y Estado constitucional, Edersa, Madrid, 1977, p. 2. 
conservadoras, convirtiéndose, en no pocas ocasiones, en instrumento de poder en manos dictatoriales, que han abusado de la falta de filtro que la representación supone, sobre todo en países u ocasiones en que la opinión pública, poco formada, resulta especialmente manejable.

Esa posible utilización de una versátil opinión pública ha sido una de las causas principales, pero no la única, de la primacía actual de la democracia representativa como forma de participación política. A esa razón habría que añadir otras.

Por ejemplo, que la masificación y complejidad de la sociedad y la necesidad de tomar decisiones rápidas y altamente tecnificadas han provocado, incluso, la crisis de instituciones como el propio Parlamento en el ejercicio de lo que es, por otro lado, una de sus funciones principales -la de legislarlo que ha provocado que, progresivamente, y por el contrario, los Gobiernos hayan aumentado su actividad en ese campo a través de las diversas formas de legislación delegada, o de urgencia, o, simplemente, a través de una mayor actividad de iniciativa legislativa. Con mayor razón aún, la crisis, por tales motivos, alcanza con más contundencia a la propia democracia directa.

En la pugna entre democracia directa y democracia representativa no han faltado, sin embargo, soluciones doctrinales partidarias de sostener la complementariedad entre ambas formas de participación. Así lo expuso el propio Condorcet, al que siguieron en esa línea Weber, Bobbio, Preuss y Carré de Malberg en su Contribución a la teoría general del Estado. Pero no ha pasado de ser mera elaboración doctrinal, superada por la primacía de la participación popular a través de los representantes.

Antes de entrar a analizar la solución adoptada por la Constitución vigente en España desde 1978, cabe hacer una última aclaración teórica sobre una cuestión más semántica que otra cosa.

En sentido estricto, no puede hablarse de democracia directa en ninguno de los institutos que tratan de realizarla en la práctica, y que a continuación examinaremos, porque la identidad perfecta entre el sujeto y el objeto del poder político que la democracia directa supone, no se da en la realidad de manera total. El pueblo no actúa con absoluta presencia, a través de toda la Comunidad. Numérica o materialmente faltan los requisitos para que pueda calificarse de directa, en sentido estricto.

Todo ello sin tener en cuenta que, en muchas ocasiones, la práctica de la democracia directa suele ir, en algún caso, precedida de manifestaciones de ejercicio de la democracia representativa. Estos datos llevan, en la realidad, a que la democracia directa sea semi-directa, sin que eso suponga el que no pueda usarse indistintamente ambas expresiones. En cualquier caso, el matiz debe ser recogido ${ }^{2}$.

2. Cfr. Pérez Serrano, Nicolás: Tratado de Derecho Político, Civitas, Madrid, 1976, p. 706; actualmente apunta la distinción Fernández Segado, FCo.: El sistema constitucional español, Dykinson, Madrid, 1992, p. 118. 
Aunque más tarde se pase a examinar la solución española respecto al tema que nos ocupa, bueno será adelantar que la Constitución de 1978 recoge el derecho de participación en su artículo 23.1: "Los ciudadanos tienen el derecho a participar en los asuntos públicos, directamente o por medio de representantes, libremente elegidos por sufragio universal. A través de su enunciado se formulan ambos modos de ejercer la democracia.

\section{LAS INSTITUCIONES DE DEMOCRACIA DIRECTA}

La vía abierta por el artículo 23.1 de la Constitución española a la democracia directa podría provocar el espejismo de creer que estamos ante una solución mixta o complementaria entre participación directa y participación representativa. No es así. Como ya se sabe, y luego se insistirá, la opción constitucional se sitúa - no podía ser de otra manera- muy a favor de la segunda forma de participación.

Todo ello no impide que se repase, a continuación, el panorama actual de la democracia directa, lo que permitirá la aproximación a la institución objeto de estudio. En el Derecho Comparado, la democracia directa actúa, fundamentalmente, a través de las cuatro instituciones que se detallan a continuación.

A) La "Landsgemeinde" -comunidad de la tierra, Asamblea Popular, se ha traducido en ocasiones- supone la reunión de todos los habitantes para deliberar juntos y resolver cuestiones relacionadas con su comunidad. Su objeto no se limita a la vida local, sino que se extiende a otros aspectos de los cantones suizos, lugar en donde esta institución alcanza su pleno contenido. Pese a ello, también en la propia Confederación Helvética, su uso ha ido a menos. Si en el siglo XVIII podían contabilizarse hasta once cantones en los que estaba vigente, en el siglo XIX eran ocho, y en la actualidad son cinco los cantones en donde las Asambleas Populares, mezcla de fiesta, política y rito, mantienen esa vigencia.

La reducida extensión territorial y una colectividad relativamente homogénea hacen posible la pervivencia de esta institución, que ha venido desarrollando funciones tan importantes como la propia revisión constitucional, la aprobación de leyes, elaboración de presupuestos, establecimiento de impuestos, elección de jueces y de funcionarios, etc...

Pérez Serrano, tras citar a Brooks, quien describía a las Asambleas helvéticas como "la institución más pintoresca y fascinadora de Suiza y, quizá, del mundo", añade: "Esa Asamblea que no es sólo Cuerpo Legislativo, sino casi servicio religioso en que el Pueblo toma parte, constituye una venerable reliquia, digna del respeto que merece lo tradicional no dañino, en un ambiente patriarcal, a la sombra del templo, junto al bosque poblado, bajo la montaña ingente ${ }^{3}$.

3. Pérez Serrano, Nicolás: Tratado de Derecho Político, op. cit., p. 699. 
En nuestros días, las Asambleas Populares suizas son una institución en retroceso, puro vestigio de naturaleza enraizada más en lo típico que en criterios de eficacia jurídica. Pero, en los cantones en que pervive, el pueblo ejerce, efectivamente, ese poder supremo a través de una reunión anual ordinaria - a celebrar el último domingo de abril, o el primero de los de mayo- o de las extraordinarias, que el Consejo Cantonal convoca cuando estima oportuno, o cuando lo solicitan determinado número de habitantes de esos cantones.

Pese a lo que parezca, no están exentas esas Asambleas Populares de determinados inconvenientes, pues, como señala García Pelayo, " la Landsgemeinde significa formalmente la más pura expresión de la democracia directa; pero la publicidad de las votaciones la hace especialmente apta para convertirsé en una oligarquía si el cantón en cuestión carece de una estructura que asegure la independencia económica de sus miembros, y, como esto no sucede en todos los cantones, se da así el caso de que ciertas magistraturas estén de hecho vinculadas a unas cuantas familias" ${ }^{4}$.

Con cierta similitud formal, que no material, con la" "Landsgemeinde", puede encontrarse en España el Concejo Abierto, como órgano de gobierno municipal que funciona, con determinadas características y en circunstancias especiales, en lugar del Ayuntamiento en Pleno. Características y circunstancias que son fruto de costumbres inveteradas. Así, el último inciso del artículo 140 de la Constitución remite a una ley posterior -concretamente ha sido la Ley de Bases de Régimen Local- la regulación de "las condiciones en las que proceda el régimen del Concejo Abierto".

El artículo 29 de la Ley de Bases de Régimen Local establece el Concejo Abierto para los Municipios de menos de cien habitantes y para los que "tradicionalmente cuenten con este singular régimen de gobierno y administración" y para "aquellos otros en los que su localización geográfica, la mejor gestión de los intereses municipales o otras circunstancias lo hagan aconsejable». Para que se constituyan en Concejo Abierto la Ley exige "petición de la mayoría de los vecinos, decisión favorable por mayoría de dos tercios de los miembros del Ayuntamiento y aprobación de la Comunidad Autónoman.

En el régimen de Concejo Abierto, el gobierno y la administración municipales corresponden a un Alcalde y a una Asamblea Vecinal, de la que forman parte todos los electores. Ajustan su funcionamiento a los usos, costumbres y tradiciones locales y, en su defecto, a lo establecido en la Ley de Bases de Régimen Local y a la legislación de las Comunidades Autónomas sobre esta materia. Este es el caso, por ejemplo, de la Ley sobre demarcación territorial de los Concejos del Principado de Asturias.

Los órganos de gobierno de los Concejos Abiertos son la Asamblea Vecinal y el Alcalde, elegido por los vecinos conforme al sistema mayoritario. En

4. García Pelayo, Manuel: Derecho Constitucional Comparado, Alianza Universidad, Madrid, 1984, p. 556. 
este régimen desaparecen, por tanto, los concejales como órganos representativos de los electores.

La mención de los Concejos Abiertos que realiza la Constitución en su artículo 140 , no estuvo, pese a lo que pueda parecer, exenta de debate en sede constituyente. La plasmación constitucional realizada fue el resultado de una fórmula pactada propuesta por el diputado Peces Barba, tratando de armonizar un criterio restrictivo de tal institución, formulado por el diputado Cisneros Laborda, y otro en un sentido aperturista, que propugnó el también diputado Fraga Iribarne ${ }^{5}$.

B) La revocación o "recall", en denominación norteamericana, es una institución que permite dejar sin efecto, a través de una decisión popular directa, a un funcionario o cargo público previamente elegido por el mismo cuerpo electoral que ahora lo destituye. También permite que una fracción del cuerpo electoral pueda reclamar la celebración de nuevas elecciones para renovar cargos -parlamentarios incluidos- anteriormente elegidos

Está vigente en algunos estados miembros de los Estados Unidos de Norteamérica, en algunos cantones suizos, y estuvo parcialmente vigente en el último texto constitucional de la extinta Unión Soviética.

Examinadas, siquiera brevemente, estas dos formas de democracia directa que no tienen aplicación ninguna en España, cabe detenerse, con cierta mayor amplitud, en el referéndum.

C) El referéndum es uno de los mecanismos de participación directa del ciudadano en la vida política, consistente en formular una pregunta al cuerpo electoral para que éste se pronuncie, afirmativa o negativamente, sobre la misma, sin ningún tipo de intermediarios.

El origen de esta institución debe encontrarse en el Antiguo Régimen, cuando estaba vigente el mandato imperativo de los representados a los representantes. Cuando éstos carecían de instrucciones concretas a la hora de tomar alguna decisión que se había planteado sin tiempo previo para que evacuaran consultas a sus representados, evitaban emitir opiniones definitivas, sino que lo hacían provisionalmente, "ad referendum", o sea, refiriendo dicha opinión, o respuesta, definitiva a sus representados, quienes debían ratificar esa primera opinión emitida sin esas consultas, pendiente de las mismas.

Posiblemente fuera Segismundo Moret quien utilizara el término referéndum por vez primera en España para relacionarlo con su sentido técnico propio. También entre nosotros, el primer trabajo científico sobre este instituto se produce en 1917, y su autor fue Julián de Repáraz y Astein.

El referéndum alcanzó rango constitucional por vez primera en España en el texto de 1931. En virtud de su artículo 66, el pueblo podía "atraer a su decisión mediante referéndum las leyes votadas por las Cortes".

Pero, como tantas previsiones de aquélla República y de aquélla Constitución, también la correspondiente al referéndum quedaría en papel mojado.

5. Cfr. Diario de Sesiones del Congreso de los Diputados, núm. 88, 14 de junio de 1978. 
Ni tan siquiera llegó a aprobarse la ley que, según la regulación constitucional, debía desarrollarlo.

En el sistema de las Leyes Fundamentales del general Franco, la Ley de Referéndum Nacional, de 22 de octubre de 1945, consagraba la institución del referéndum legislativo, atribuyéndose exclusivamente la iniciativa del mismo al Jefe del Estado. Se trataba de un referéndum de carácter facultativo y no vinculante. Se preveía su utilización como instrumento de consulta popular, cuando la trascendencia de determinadas leyes lo aconsejaran o lo demandase el interés público. Más tarde, el artículo 10 de la Ley de Sucesión en la Jefatura del Estado, de 27 de julio de 1947, dispondría que la derogación o modificación de las Leyes Fundamentales requería, además del acuerdo de las Cortes, la consulta popular mediante el referéndum.

La Constitución española de 1978, tras intensos debates parlamentarios, ha consagrado cuatro grandes modalidades de referéndum (de reforma constitucional, consultivo, autonómico y municipal), alguna de las cuales engloba, a su vez, varias subespecies netamente diferenciadas. Respecto al uso, por otra parte parco, que se ha hecho de esta previsión constitucional cabe señalar que no es éste el lugar indicado para profundizar en ello, aunque puede insinuarse que no ha servido tal uso precisamente para prestigiar la institución.

D) La cuarta institución de democracia directa es la iniciativa legislativa popular, objeto principal de este trabajo. A ella, lógicamente, se dedica el resto del mismo.

\section{LA INICIATTVA LEGISLATIVA POPULAR. ANTECEDENTES}

Puede entenderse, con el profesor Biscaretti di Ruffia, que la iniciativa legislativa popular es la atribución a una determinada fracción del cuerpo electoral de la facultad de iniciar el procedimiento de formación de la ley formal ${ }^{6}$.

$\mathrm{Al}$ igual que ocurre con las restantes formas de democracia directa, la iniciativa legislativa popular no se ha visto libre del recelo y de la desconfianza de legisladores y políticos. Así lo ha visto también la doctrina en Italia, cuna de buena parte de los estudios sobre esta institución. En efecto, el profesor Dirce Bezzi, reflexionando sobre la experiencia de su propio país, escribe: "Il primo dato che emerge per chi si accinge ad intraprendere uno studio sull' $i$ niziativa legislativa popolare è la sottovalutazione, la poca atenzione, in alcuni casi la vera e propria "liquidazione" che questo istituto ha subito nel corso dello sviluppo del nostro ordinamento, dal 1947, in poi, e della nostra storia politica" 7 . 423.

6. Cfr. Biscaretti di RufFìa, Paolo: Derecho Constitucional, Tecnos, Madrid, 1987, pp. 422-

7. BEzzI, Dirce: Iniziativa legislativa popolare e forma di governo parlamentare, Giuffrè Editore, Milano, 1990, p.1. 
La crítica transcrita hay que enmarcarla, como anteriormente se ha señalado, dentro del escaso, o casi nulo, interés que las modalidades de democracia directa suscitan en el Derecho Constitucional actual.

En relación con los antecedentes, hay que hacer notar que el único existente en el Derecho histórico español es el del artículo 66 del texto de la Segunda República, en 1931. En su párrafo tercero, el citado artículo atribuía al pueblo el ejercicio del derecho de iniciativa, presentando a las Cortes una proposición de ley, siempre que fuera avalada, al menos, por un número de firmas superior al quince por ciento de los electores. Tal exigencia numérica, ciertamente excesiva, hacía que la institución regulada naciera ciertamente mermada en cuanto a sus posibilidades reales de utilización. Por lo demás, las restantes cuestiones que podían suscitar el desarrollo y regulación de este instituto se remitían a una posterior ley especial , que nunca llegaría a aprobarse.

El precepto citado no figuraba en el Proyecto constitucional, y se introdujo merced a un voto particular del diputado Castrillo. La Comisión constitucional estableció el mínimo de proponentes de la iniciativa legislativa en un veinte por ciento del total del censo electoral, atendiendo a la propuesta de Trifón Gómez. La discusión final redujo el porcentaje exigido.

A este respecto, comentando el citado artículo, que daba rango constitucional a la iniciativa legislativa popular, afirmaba el profesor Pérez Serrano: “La desconfianza en el Pueblo implica siempre una grieta en la fe democrática; y no cabe tener confianza en el sujeto para fundar sobre él todo el Estado, y experimentar luego inquietudes sobre su competencia cuando esa soberanía ha de actuarse en una materia determinada $"$.

$\mathrm{Si}$, como puede apreciarse, los precedentes en nuestro Derecho histórico, son escasos, tampoco el panorama extranjero ofrece muchos más antecedentes en lo referente a la institución objeto de estudio.

En Suiza, en el ámbito federal, la iniciativa popular, basada en la firma de cincuenta mil ciudadanos con derecho a voto, sólo es posible en materia de reforma constitucional, quedando excluida en lo tocante a la legislación ordinaria a nivel federal. En el ámbito cantonal, sin embargo, la iniciativa popular se admite tanto para proponer la reforma constitucional como para la legislación ordinaria. Y no conviene olvidar que tales restricciones se producen en el país abanderado del ejercicio práctico de las formas de democracia directa.

Ni Francia ni Alemania otorgan rango constitucional a la iniciativa legislativa popular. Tampoco en los Estados Unidos de Norteamérica se reconoce su existencia a nivel federal. Sin embargo, se admite en bastantes Estados miembros de la Unión, -veintidós, en concreto- fundamentalmente del

8. Pérez Serrano, Nicolás: La Constitución española (9 diciembre de 1931). Antecedentes, texto, comentarios. Editorial Revista de Derecho Privado, Madrid, 1932, p. 244. 
Oeste. Alaska ha sido el último de los Estados miembros en incorporarse a esta lista.

Quizá sea Italia el ejemplo más interesante. El artículo 71 de su Texto Constitucional de 1947 recoge la posibilidad de que el pueblo ejercite "la iniciativa de las leyes mediante la propuesta, efectuada por, al menos, cincuenta mil electores, de un proyecto redactado en artículos".

En todo caso, y conviene precisarlo ahora, a propósito del caso italiano, hay que evitar la confusión entre iniciativa legislativa popular, que exige que las Cámaras tramiten una propuesta de ley ya elaborada -como ocurre en España-, o que éstas inicien el procedimiento para legislar sobre determinada cuestión, con la solicitud, por el electorado, de un referéndum legislativo que recae sobre un proyecto ya elaborado por las Cámaras, solicitud que, por lo tanto no inicia el procedimiento legislativo'. Evidentemente, aquí interesa lo que es, estrictamente, la iniciativa legislativa popular.

\section{LA REGULACION DE LA INICIATIVA LEGISLATIVA POPULAR EN LA VIGENTE CONSTITUCION ESPAÑOLA}

El Anteproyecto constitucional (Boletín Oficial de las Cortes Generales de 5 de enero de 1978) establecía en su artículo 80.4: "Podrán someterse al Congreso proposiciones de ley articuladas y motivadas, con las firmas acreditadas de quinientos mil electores. La iniciativa popular no procede en materia tributaria, de carácter internacional, ni en lo relativo a la prerrogativa de gracia. La ley regulará el ejercicio de este derecho".

El Informe de la Ponencia del Congreso no modificó en nada el texto del Anteproyecto. El cambio se produciría en el Dictamen de la Comisión de Asuntos Constitucionales de esa Cámara, a raíz de una enmienda pactada por varios grupos parlamentarios, merced a la cual la redacción del entonces artículo 81.4 quedaba plasmada de la siguiente manera (Boletín Oficial de las Cortes Generales de 1 de julio de 1978): “Una ley orgánica regulará las formas de ejercicio y requisitos de la iniciativa popular para la presentación de proposiciones de ley. En todo caso se exigirán no menos de 500.000 firmas acreditadas y no procederá en materia tributaria o de carácter internacional, ni en lo relativo a la prerrogativa de gracia".

El Pleno del Congreso de los Diputados no modificó ni la redacción ni la numeración del precepto transcrito. Pocas variaciones hubo en el Senado. Modificó sólo su numeración, pasando a ser el 86.3 .

Fue la Comisión Mixta Congreso-Senado quien le daría su numeración definitiva, artículo 87.3, y su redacción final, que poco variaba de la transcri-

9. Cfr. a este propósito Jiménez de Cisneros, F.J.: "El derecho de petición y la iniciativa legislativa" en Cuadernos de Documentación, Instituto Nacional de Prospectiva, núm.25, 1980, p. 52. 
ta en último lugar. Razones gramaticales aconsejaron añadir un punto y seguido, y a los supuestos en que no procedía la iniciativa popular se incorporó el de las "materias propias de ley orgánica".

Todo ello llevaba a que la redacción definitiva del artículo 87 de la Constitución española de 1978 fuera del siguiente tenor:

"1. La iniciativa legislativa corresponde al Gobierno, al Congreso y al Senado, de acuerdo con la Constitución y los Reglamentos de las Cámaras.

2. Las Asambleas de las Comunidades Autónomas podrán solicitar del Gobierno la adopción de un Proyecto de Ley o remitir a la Mesa del Congreso una proposición de ley, delegando ante dicha Cámara un máximo de tres miembros de la Asamblea encargados de su defensa.

3. Una ley orgánica regulará las formas de ejercicio y requisitos de la iniciativa popular para la presentación de proposiciones de ley. En todo caso se exigirán no menos de 500.000 firmas acreditadas. No procederá dicha iniciativa en materias propias de ley orgánica, tributarias o de carácter internacional, ni en lo relativo a la prerrogativa de gracia..

Para el profesor Solé Tura, la regulación constitucional combinaba adecuadamente la democracia directa con la representativa. Para el profesor Fraga Iribarne, en opinión manifestada también en la misma sede parlamentaria -el Congreso de los Diputados-, la inclusión en la Constitución de determinadas manifestaciones de democracia directa era una necesaria compensación de raíces profundamente populistas y democráticas ${ }^{10}$.

En la redacción final del precepto objeto de estudio, la intervención del profesor Alzaga Villamil fue decisiva. En sede parlamentaria ya advertía que la iniciativa popular carecía de tradición, incluso en países europeos de larga historia democrática, exceptuando Suiza - experiencia singular y difícilmente trasladable»- e Italia, en donde la experiencia, "a juicio de la doctrina más generalizada, ofrece resultados contradictorios y a sopesar con cuidado" ${ }^{11}$.

El examen de la regulación constitucional de la institución en estudio debe terminar, necesariamente, con la referencia a su ley de desarrollo, anunciada en el propio artículo 87.3. Se trata de la Ley Orgánica 3/1984, de 26 de marzo, reguladora de la iniciativa legislativa popular.

\section{NATURALEZA JURIDICA DE LA INICIATIVA LEGISLATIVA POPULAR}

El examen de la naturaleza de la institución objeto de un estudio es, posiblemente, uno de los aspectos centrales del mismo. No es una excepción a este regla la iniciativa legislativa popular, el examen de cuya naturaleza, a la

10. Diario de Sesiones del Congreso de los Diputados, sesión de 6 de junio de 1978.

11. Ibidem, sesión de 2 de junio de 1978 . 
que hay que referirse necesariamente en este trabajo, sitúa frente a una serie de cuestiones complejas, de hondo calado, y muy discutidas, que se tratará de analizar a continuación.

Conviene recordar, en primer lugar, que el estudio del Derecho Constitucional lleva consigo, ineludiblemente, el examen de los fenómenos de poder. Carré de Malberg advirtió, a este propósito, que la sociedad es una constelación de poderes.

Todo poder lleva consigo la existencia de un sujeto, que ejerce ese poder, y un objeto, sobre el que recae la acción del mismo, así como un conjunto de relaciones entre ambos. Por lo mismo, la propia actividad del poder estatal, que, concebido en sentido amplio, equivaldría al poder político, supone la aparición de un conjunto de relaciones entre el sujeto y el objeto del mismo.

Mediante la participación política, se articulan los mecanismos de relación entre el sujeto y el objeto del poder político. Esa participación queda configurada en un Estado democrático más allá de un simple hecho, como algo consustancial a su misma naturaleza.

Pero no siempre ha existido esa relación necesaria entre Estado y participación de los ciudadanos. No hay que olvidar que el Estado es un fenómeno histórico, que ha ido evolucionando a lo largo del tiempo. A este propósito convendrá recordar que el tránsito del Estado absoluto al Estado liberal, operado fundamentalmente con la Revolución por antonomasia, la francesa, supone, entre otras muchas consecuencias, la conversión de los súbditos en ciudadanos, y la aparición de una incipiente participación política de los mismos.

Tal participación se articulará, en principio y fundamentalmente, a través del sufragio censitario. Será en las postrimerías del siglo XIX o comienzos del XX -según los países- cuando el Estado liberal de Derecho se transformará en democrático, sobre todo mediante la transformación del sufragio en universal, lo que se opera primero en el ámbito masculino, generalizándose después, y convirtiéndose así en estrictamente "universal". Esa transformación democrática del Estado corre de la mano de la afirmación doctrinal de la soberanía popular, frente a la soberanía nacional surgida ésta de la doctrina inmediatamente precursora de la Revolución francesa.

La participación se nos presentará, pues, como un derecho de los ciudadanos en el Estado liberal. Más tarde, con el Estado democrático, la participación se convierte en algo exigido por la misma naturaleza del Ëstado.

En la línea expuesta, encontramos el artículo 23 de nuestro Primer Texto Legal, anteriormente transcrito. Tal precepto, por una parte, otorga rango constitucional a un derecho -el de participación- y, por otra, es una consecuencia necesaria del carácter democrático del Estado español, recogido expresamente como principio esencial en el Preámbulo constitucional y en el artículo 1, e indirectamente, en otros muchos artículos del Texto de 1978.

A propósito de la participación como un derecho, comenta el profesor Santamaría Pastor, en línea con lo apuntado en precedentes párrafos, que no 
es «un derecho o libertad pública más, sino la auténtica vertiente subjetivizada de toda la estructura democrática del Estado" ${ }^{12}$.

El tratamiento constitucional de la participación política la sitúa como un derecho de entre los enumerados en el título I, capítulo $2 .^{\circ}$, sección $1 .^{a}$, de la que forma parte el citado artículo 23. Por tanto, estamos en presencia de un derecho fundamental, que lleva consigo, además, una especial protección jurisdiccional, como ocurre con todos los derechos fundamentales, calificación que la Constitución otorga a los recogidos en dicho lugar.

La solución constitucional adoptada obliga, pues, a una consideración bifronte de la naturaleza jurídico-constitucional de la participación política, al considerarla, por un lado, como una manera de vertebrar un principio esencial del Estado -función estructural-y, por otro lado, como un derecho fundamental, de más amplio y generoso contenido que el que se le concedió en textos constitucionales anteriores. Así pues, la participación nos exige una consideración doble y complementaria.

Ese mismo criterio de consideración bifronte de la participación política en la Constitución de 1978 ha sido recogido por el Tribunal Constitucional en su Sentencia 51/1984, de 25 de abril, manifestando que "se trata de un derecho fundamental, que encarna el derecho de participación política en el sistema de un Estado social y democrático de Derecho".

Hechas las precisiones precedentes respecto al derecho de petición, convendrá ahora dar un paso más, y adentrarse en la relación de la iniciativa legislativa popular con el derecho citado, primero de los aspectos a tratar en lo referente a la naturaleza de la iniciativa legislativa popular.

Conviene recordar, para empezar, que la iniciativa legislativa popular es una institución de democracia directa, por la que un grupo de ciudadanos presentan al órgano del poder legislativo -las Cortes- una proposición de ley para que ese órgano ponga en funcionamiento el correspondiente procedimiento de elaboración y, en su caso, aprobación de las leyes.

La iniciativa popular se nos presenta, también, de manera bifronte. Por un lado, como una manifestación instrumental de un derecho fundamental -el de participación política- y por otro, y como consecuencia de lo anterior, se nos aparece como una concreción del carácter democrático del Estado, tal como ocurre con el derecho de participación, al que la iniciativa popular queda uncida. Sin embargo, y para adentrarnos algo más, habrá que realizar alguna precisión.

En primer lugar, puede afirmarse que la iniciativa legislativa popular -a diferencia del derecho de participación- no es una consecuencia necesaria de la naturaleza democrática del Estado. Así, hay Estados manifiestamente democráticos que no reconocen instituciones de participación directa, como antes

12. Santamaría Pastor, Juan Alfonso: "Artículo 23" en Comentarios a la Constitución (dirigidos por F. Garrido Falla), Civitas, Madrid, 1985, p.443. 
se ha ejemplificado, y, a mayor abundancia, hay países que han incorporado a su ordenamiento instituciones de democracia directa $y$, sin embargo, no reconocen entre ellas la iniciativa legislativa popular. No hay, pues, una relación necesaria, una correlación, entre iniciativa popular y Estado democrático. Del mismo modo que sí la hay entre éste y la participación.

Por otro lado, cabe llegar a la conclusión de que la iniciativa legislativa popular más que un derecho en sí misma, es una manifestación instrumental del derecho de participación política. Así, no hay un derecho a la iniciativa legislativa popular, y sí que hay un derecho de participación, uno de cuyos modos de realizarse o instrumentarse es la mencionada iniciativa.

Sin embargo, y, pese a ese carácter instrumental, su ejercicio queda protegido por el recurso de amparo ante el Tribunal Constitucional. La Ley Orgánica 3/1984, de 26 de marzo, que desarrolla la iniciativa legislativa popular (en adelante, LOILP) establece, en su artículo 6 , la posibilidad de acudir al amparo constitucional contra la decisión de no admitir a trámite dicha iniciativa por parte de la Mesa del Congreso de los Diputados. Precepto que hay que relacionar con el artículo 42 de la Ley Orgánica del Tribunal Constitucional cuando incluye, como susceptibles de ser objeto del recurso de amparo, las decisiones o actos sin valor de ley emanados de las Cortes, o de cualquiera de sus órganos, o de las Asambleas Legislativas de las Comunidades Autónomas, o de sus órganos, que violen los derechos y libertades susceptibles de amparo constitucional. Esta protección de la iniciativa legislativa popular por la vía del recurso de amparo ha merecido algunas críticas de un sector de la doctrina ${ }^{13}$.

Cabe, sin embargo, matizar esas críticas. A la protección de la iniciativa legislativa popular por parte del Tribunal Constitucional se ha llegado, en definitiva, por dos vías, que, aunque no diseñadas para ese fin, han sido, podría decirse, aprovechadas para alcanzar ese resultado. La primera de esas vías viene dada por el hecho de que la iniciativa legislativa popular es, como antes se ha aclarado, manifestación instrumental del derecho de participación, el cual sí que está protegido por el recurso de amparo en su doble procedimiento, ante la jurisdicción ordinaria y ante la constitucional. La segunda vía ha sido citada también anteriormente. La negativa de la Mesa del Congreso a admitir la iniciativa es un acto no legislativo emanado de un órgano de las Cortes, y que lesiona de un derecho fundamental, el de participación. Por una u otra vía, y, sin necesidad de la expresa, y criticada, protección de la LOILP, se hubiera llegado al mismo resultado. A este asunto habrá que volver más tarde.

Otro aspecto a tener en cuenta en este apartado acerca de la naturaleza jurídica de la institución objeto de estudio es que, además de constituir una

13. Cfr. a este propósito SANTAMARÍA PASTOR, Juan Alfonso: "Artículo 87" en Comentarios a la Constitución, op.cit., p.1265 y Aragón Reyes, Manuel: "La iniciativa legislativa" en Revista Española de Derecbo Constitucional, núm.16, 1986, p. 305. 
proyección del derecho de participación política directa, la iniciativa legislativa popular se encuentra relacionada con el derecho de petición, que la Constitución ampara en su artículo 29.

En el elenco de los derechos públicos subjetivos, el de petición se nos presenta con un cierto carácter que podría calificarse como "residual". A falta del posible ejercicio de cualquier otro derecho, cuando el ciudadano ya no sabe ni qué hacer ni a quién acudir - por utilizar una expresión gráfica- siempre le queda la posibilidad de pedir, de ejercer, como recurso final, el derecho de petición.

Tanto el derecho de petición como la iniciativa legislativa popular nos colocan en situaciones en las que el pueblo actúa directamente ante los poderes públicos, tratando de conseguir de ellos determinadas conductas. Esto ha llevado a determinados autores ${ }^{14}$ a afirmar que ambas instituciones comparten la misma naturaleza, por presentar características comunes, aunque con funciones y efectos distintos.

En el caso del derecho de petición, dada su amplitud, los puntos comunes con la iniciativa popular se producen, fundamentalmente, en el hecho de que ambos pueden ejercerse colectivamente ante el Congreso de los Diputados. Pero, aun en este caso, el efecto de la petición no obliga al receptor a iniciar un procedimiento, a diferencia de lo que ocurre con la iniciativa, que, con sólo recibirla obliga al Congreso de los Diputados a iniciar un procedimiento, tal como la Ley Orgánica de la Iniciativa Legislativa Popular le obliga.

Con todo, y entramos en un tercer aspecto, el punto más debatido respecto a la naturaleza de la iniciativa legislativa popular, tal como está regulada en nuestro ordenamiento jurídico, es el de saber si se trata, o no, de una verdadera iniciativa, o, si por el contrario, estamos ante lo que podría denominarse una "propuesta de iniciativa" o una "iniciativa de iniciativa". En este tercer aspecto de la naturaleza de la iniciativa se centra el resto del presente apartado.

Para entender el problema hay que centrarse en la atribución de la titularidad de la iniciativa legislativa que realiza el artículo 87 de la Constitución. A tenor de ese precepto, son titulares de la misma el Gobierno, el Congreso de los Diputados y el Senado, el pueblo y las Comunidades Autónomas. Para centrar el tema, se puede prescindir de la titularidad atribuida a las Comunidades Autónomas, pues no afecta a la cuestión que aquí se estudia. Cabe centrarse en la iniciativa legislativa atribuida al Gobierno, a cada una de las Cámaras y al pueblo, objeto, ésta última, del presente trabajo.

Aclarado que toda iniciativa legislativa, sea cual fuere su origen, se tramita primero ante el Congreso - solución discutible en lo referente a la iniciativa autonómica, pues vuelve a poner en berlina el papel del Senado como Cámara de representación territorial- cabe recordar que cuando la iniciativa

14. Biguino CAMPos, Paloma: "La iniciativa legislativa popular en el ordenamiento jurídico estatal" en Revista Española de Derecho Constitucional, núm.19, 1987, p. 92. 
procede específicamente del Gobierno - proyecto de ley- no se requiere trámite alguno de aceptación previa de la misma por parte del Congreso. Ello es así porque, a tenor del artículo 87.1 de la Constitución, el Gobierno, como tal, es plenamente titular de la iniciativa legislativa.

En el caso de las proposiciones de ley procedentes de los diputados o senadores, sí que se requiere un trámite de aceptación previa: la toma en consideración por el Pleno de la Cámara, que es el órgano en el que se forma, y por el que se expresa, la voluntad de la Cámara como tal. Hasta entonces lo que hay es una propuesta de iniciativa, siguiendo las normas que los Reglamentos de las Cámaras imponen.

Esto es así por una razón elemental. Y es la de que el artículo 87.1 de la Constitución establece que la titularidad de la iniciativa corresponde al Congreso y al Senado, o sea, a cada una de las Cámaras. Mientras los respectivos Plenos no hagan suyas las propuestas de una parte de los correspondientes diputados o senadores no hay tal iniciativa, de la que solamente cada una de las Cámaras es titular. En este caso se entiende perfectamente la necesidad de que exista un trámite por el que cada una de las Cámaras en Pleno asuma las propuestas de un sector de las mismas. Y ese trámite es la "toma en consideración".

La cuestión problemática radica en que los artículos 126 del Reglamento del Congreso de los Diputados y 13 de la LOILP exigen que la propuesta de la iniciativa legislativa popular pase también el trámite de la "toma en consideración" por parte del Pleno de la Cámara Baja, al igual que ocurre, como acaba de exponerse, con las proposiciones de ley, fruto, en este caso, de lo que podríamos denominar como "iniciativa interna", puesto que éstas tienen su origen en la actividad proponente de los miembros de la Cámara. Es decir, que, pese a reconocerse al cuerpo electoral, manifestado en quinientas mil firmas, la titularidad de la iniciativa legislativa, se le hace pasar por el mismo trámite que a la procedente de diputados y senadores, que no tienen reconocida esa titularidad.

La solución no es ajena a la polémica, pues mientras algunos autores no muestran discrepancia con la misma ${ }^{15}$, en otros casos -a los que estas líneas se suman- la crítica es abierta. Sirva de botón de muestra la opinión del profesor Santamaría Pastor:

"Rechazar a limine, sin debate, y como si se tratase de una iniciativa descabellada e irresponsable, una proposición de esta naturaleza, es un agravio gratuito infringido a una masa de electores concienciados. Ningún grupo político sensato osaría desairar de esta forma a quinientos mil, o más, votantes, que pueden desnivelar la balanza en unas elecciones generales discutidas por márgenes escasos: una fórmula de democracia directa como la que contemplamos no puede subordinarse en su instrumenta-

15. ARAgón ReYes, Manuel: "La iniciativa legislativa", op. cit., p. 305. 
ción a la libre decisión del órgano por excelencia de la democracia representativa " ${ }^{16}$.

Conviene, en todo caso, insistir en que el artículo 87 de la Constitución atribuye a cada Cámara la titularidad de la iniciativa legislativa, y que el trámite de la toma en consideración sirve para hacer efectiva esa titularidad, haciendo suya la propuesta de un sector de parlamentarios. Pero conviene también tener presente que ese mismo artículo de nuestro Primer Texto legal atribuye a una fracción del cuerpo electoral -quinientos mil electores- esa misma titularidad, la cual debería existir desde el momento en que, admitida la propuesta a trámite por la Mesa del Congreso, recibe la adhesión de las firmas requeridas y con los requisitos exigidos por la LOILP No haría falta nada más para perfeccionar esa titularidad, por lo que la exigencia de la toma en consideración por el Congreso de los Diputados se nos aparece como un requisito, cuanto menos, superfluo, y hasta cierto punto contradictorio, a la vista del artículo 87.

Pero, retomando el hilo de la naturaleza jurídica de la institución objeto de estudio, habrá que concluir que, desde el punto de vista del diseño teórico previsto en la Constitución, la iniciativa legislativa popular es, verdadera y propiamente, una iniciativa legislativa. Con la LOILP y el Reglamento del Congreso de los Diputados en la mano, se transforma en una "propuesta de iniciativa" o en una "iniciativa de iniciativa", al exigirse que pase por el trámite de la toma en consideración.

\section{TITULARES DE LA INICIATIVA}

El artículo 23.1, antes transcrito, responde, en su tenor literal, al enunciado de este apartado, en lo referente al derecho de participación, del que se parte para iniciar la aproximación a la iniciativa legislativa popular, como se ha hecho en anteriores apartados. Así, la titularidad del derecho de participación corresponde a "los ciudadanos", tal como especifica el precepto citado.

Pero para conocer el alcance exacto de la atribución de la titularidad del derecho de participación que hace ese artículo, tal precepto debe ser cotejado con el 13.2 de nuestro primer Texto Legal que concreta que: "Solamente los españoles serán titulares de los derechos reconocidos en el artículo 23 , salvo que, atendiendo a criterios de reciprocidad, pueda establecerse por tratado o ley para el derecho de sufragio activo y pasivo para las elecciones municipales" ${ }^{17}$.

16. Santamaría Pastor, Juan Alfonso: Artículo 87, op. cit., p. 1265.

17. El artículo fue reformado el 27 de agosto de 1992 (BOE de 28 de agosto). Es la única reforma operada hasta ahora en la Constitución. 
A tenor, pues, de ambos preceptos son los nacionales españoles los titulares del derecho de participación, salvo en el caso concreto de las elecciones municipales, en las que, por tratado o ley y según criterio de reciprocidad, los extranjeros pueden gozar de la titularidad activa y pasiva.

Pero aún habrá que acudir a otro artículo de la Constitución para establecer -por analogía- qué españoles son titulares de tal derecho. Y así, es el artículo 68.5 el que, al referirse a las elecciones al Congreso de los Diputados, circunscribe la titularidad a los españoles que estén "en pleno uso de sus derechos políticos".

Todo ello nos lleva a la conclusión de que nuestra Constitución atribuye la titularidad del derecho de participación política a los ciudadanos españoles mayores de edad, no incapacitados judicialmente, bien sea por incapacidad física o psíquica, o condena. La excepción a esta regla habrá que buscarla en aquellos extranjeros con cuyo país exista reciprocidad para que sean titulares del derecho de sufragio activo o pasivo -o ambos- en las elecciones municipales. Ambas posibilidades se dan sólo, hoy por hoy, en los países de la Unión Europea, en virtud del Tratado de Maastricht.

El artículo 1 de la LOILP atribuye la iniciativa legislativa prevista en el artículo 87.3 de la Constitución a "los ciudadanos españoles mayores de edad que se encuentren inscritos en el censo electoral». El examen de la titularidad de la iniciativa no presenta, en principio, excesivas dificultades, ya que con esta concreción de la Ley de desarrollo se completa la laguna existente en la Constitución, que nada especifica respecto a la titularidad, limitándose a señalar el requisito del número de firmas.

La solución legal adoptada resulta congruente. La equiparación de la titularidad para ejercer la iniciativa con la capacidad electoral activa es lógica, toda vez que la importancia de ejercer la primera de ellas es comparable con la del ejercicio del derecho de voto, que supone la plenitud de la condición de ciudadano. La equiparación es fruto de la propia naturalèza de la iniciativa, que, al fin y al cabo, es una atribución otorgada a una fracciôn del cuerpo electoral.

Todo ello nos lleva a acudir a la Ley Orgánica 5/1985, de 19 de junio, del Régimen Electoral General, concretamente a sus artículos 2 y 3, que establecen los requisitos positivos y negativos para el ejercicio del derecho de sufragio.

La mayoría de edad, la inscripción en el censo electoral vigente, y el no estar comprendido en ninguno de los supuestos del artículo 3 de la mencionada Ley Orgánica, son las condiciones exigidas por el artículo 2 del mismo cuerpo legal para el ejercicio del derecho de sufragio.

De acuerdo con el artículo 3 de la misma Ley, carecen del derecho de sufragio: los condenados a esa exclusión por sentencia judicial firme, los incapacitados expresamente para tal ejercicio por sentencia judicial firme, y los internados en un centro psiquiátricọ con autorización judicial, cuando la misma declare expresamente la incapacidad para ejercer el sufragio. Los jueces y tribunales que la declaren deben comunicarla al Registro Civil para que se efectúe la anotación correspondiente. 
Queda aún un último aspecto para concluir la cuestión de la titularidad del derecho de participación y de la iniciativa legislativa popular, y es saber si dicha titularidad puede, o no, predicarse de las personas jurídicas, o, si por el contrario, se circunscribe a las personas físicas solamente.

El Tribunal Constitucional, en la ya citada Sentencia 51/1984, de 25 de abril, aclara que el derecho de participación política "no es un derecho que pueda reconocerse genéricamente a las personas jurídicas".

Esa característica de la titularidad del derecho de participación política, por la que ésta se atribuye sólo a las personas físicas, venía ya expuesta implícitamente por el propio Tribunal en Sentencia anterior -la 5/1983, de 4 de febrero- que expresaba que: "El derecho a participar corresponde a los ciudadanos, y no a los partidos...; los representantes elegidos lo son de los ciudadanos, y no de los partidos, y...la permanencia en el cargo no puede depender de la voluntad de los partidos, sino de la expresada por los electores a través del sufragio expresado en elecciones periódicas".

Respecto al posible ejercicio de la iniciativa legislativa popular por personas jurídicas, poco hay que comentar por ser totalmente imposible de acuerdo con la propia literalidad de la Constitución como, por consecuencia, con la LOILP Ambos textos legales atribuyen la titularidad de la iniciativa a personas físicas, concretando la Ley Orgánica que se trata de ciudadanos mayores de edad y con plena capacidad electoral activa, como ya se ha tenido ocasión de examinar. De tal regulación no puede inferirse ninguna posibilidad en favor de la ampliación de la titularidad a las personas jurídicas, la cual sería, a todas luces, disparatada. Hay que tener en cuenta, además, que una persona jurídica interesada en apoyar o llevar adelante una determinada iniciativa puede constituirse en Comisión Promotora, e ir sumando adhesiones individuales a su causa.

A lo dicho anteriormente hay que añadir algo más. Aunque la iniciativa se concrete en una titularidad individual, física, requiere, para su eficacia, un ejercicio colectivo. Dicho de otro modo, el titular de la iniciativa sólo es la persona física, pero se necesita un total de quinientos mil titulares individuales puestos de acuerdo para que pueda hablarse de iniciativa legislativa popular.

\section{OBJETO DE LA INICIATIVA LEGISLATIVA POPULAR}

La Exposición de Motivos de la LOILP advierte, a propósito del objeto o contenido de la iniciativa, que ula regulación constitucional de la iniciativa legislativa popular recoge las limitaciones propias de este instituto, derivadas de las enseñanzas históricas, que demuestran la facilidad con que el recurso al pronunciamiento popular directo puede servir de fácil cauce para manipulaciones demagógicas o, incluso, para intentar legitimar con un supuesto consenso popular, lo que no es en sustancia sino la antidemocrática imposición de la voluntad de una minoría. De ahí que la Constitución, amén de excluir de la iniciativa popular campos normativos particularmente delicados, encomiende al legislador la misión de 
regular, mediante Ley Orgánica, la forma concreta de ejercicio de la iniciativa popular": Y añade más adelante: "Así, quedan excluidas de la iniciativa legislativa popular no sólo las materias que lo están expresamente por obra del artículo 87.3 de la Constitución, sino también aquellas otras cuya iniciativa reguladora reserva la Norma Fundamental a órganos concretos del Estadon.

La mejor manera de desarrollar este epígrafe es a través de un estudio negativo, es decir, examinando las materias sobre las que no puede recaer la iniciativa popular, que, por tanto, no pueden constituir su objeto.

El artículo 87.3 de la Constitución establece, como antes se ha transcrito, que "no procederá dicha iniciativa en materias propias de ley orgánica, tributarias o de carácter internacional, ni en lo relativo a la prerrogativa de gracia". Cabe examinar, por separado y de manera sucinta, cada una de estas materias:

Las materias propias de ley orgánica. Esta escueta fórmula produce, necesariamente, una remisión al artículo 81 de la Constitución, el cual atribuye el carácter de orgánicas a las leyes relativas al desarrollo de los derechos fundamentales y de las libertades públicas (es decir, los enumerados en la Sección Primera del Capítulo Segundo del Título Primero), las que aprueben los Estatutos de Autonomía y el régimen electoral general y las demás previstas en la Constitución (más de cien en total) ${ }^{18}$.

No se trata entrar aquí y ahora a examinar la discusión sobre el alcance de las leyes orgánicas. La cuestión ha sido ampliamente debatida en sede parlamentaria, en sede jurisdiccional y en sede doctrinal. Reflejar ahora esa polémica no haría sino alejarnos de nuestro objeto, pese al interés que suscita la discusión. Basta señalar, como se ha hecho, las materias que quedan excluidas de la iniciativa popular en virtud de su reserva a ley orgánica.

Las materias propias de leyes tributarias. Esta exclusión resulta a todas luces lógica, pues una inadecuada utilización de la iniciativa legislativa popular en estos casos podría originar situaciones demagógicas, que pondrían en almoneda al Estado democrático representativo.

Las leyes de carácter internacional. La exclusión de las normas que incidan en esta materia también parece razonable. La dirección de la política exterior corresponde al Gobierno de la Nación. Las Cortes intervienen en lo relativo a los Tratados internacionales. La complicada urdimbre de relaciones que puede originar la política internacional, hace aconsejable esta sustracción de la iniciativa legislativa popular. Estamos, pues, ante una causa de naturaleza política, que se completa con el hecho de la atribución constitucional de competencias en favor de las Cortes Generales, en virtud del Capítulo Tercero del Título Tercero.

La prerrogativa de gracia. Tal prerrogativa es atribuida formalmente al Rey, en virtud del artículo 62.i de la Constitución. Pero se trata, como en tantos otros casos, de un acto de naturaleza debida, en el que quien decide real-

18. Sobre el tema de las leyes orgánicas puede verse el conocido trabajo del profesor PÉREZ Royo, Javier: Las fuentes del Derecbo, Tecnos, Madrid, 1988, sobre todo las pp. 57-87. 
mente es el Consejo de Ministros. La vía abierta a una posible utilización demagógica, que usaría como vehículo la iniciativa legislativa popular, sirve de razón suficientemente justificativa de esta excepción.

Las limitaciones referentes a las materias tributarias, las de carácter internacional y las relativas a la prerrogativa de gracia ya aparecían recogidas en el Anteproyecto de Constitución (Boletín Oficial de las Cortes de 5 de enero de 1978) y su similitud con el artículo 75 del Texto Constitucional italiano parece fuera de toda duda.

Además de las limitaciones expresadas en el artículo 87.3 de la Constitución, que acabamos de examinar, hay otras excepciones a la iniciativa legislativa popular por razón de su objeto. Tales limitaciones proceden de la interpretación, a sensu contrario, de algunos preceptos constitucionales. Señalamos aquí estos preceptos y estas materias:

Los Presupuestos Generales del Estado. En virtud de lo establecido en el artículo 134.1 y 3 de la Constitución, que atribuye al Gobierno la elaboración y presentación de los Presupuestos Generales del Estado, es evidente que quedan, por tanto, excluidos de toda iniciativa -la popular incluida- que no sea la gubernamental.

Los proyectos de planificación de la actividad económica general. Por razón idéntica a la expresada en el párrafo anterior. El monopolio de la iniciativa gubernamental viene recogido, en este supuesto, en el artículo 131.2 del Texto Constitucional.

El profesor Ramón Punset, comentando las dos exclusiones anteriores -que se recogen también en el artículo 2 de la LOILP- entiende que "este género de iniciativas se halla igualmente comprendido dentro del ámbito de aplicación del artículo 134.6n, que exige la conformidad del Gobierno para la tramitación de toda proposición "que suponga aumento de los créditos o disminución de los ingresos presupuestarios ${ }^{19}$. Por lo que, también por esta exigencia, quedarían excluidos de la posible iniciativa legislativa popular.

La reforma constitucional. Razones de prudencia política, y la apuesta en favor de la democracia representativa que ha hecho nuestra Constitución, excluyen de la iniciativa legislativa popular la posibilidad de plantear la reforma constitucional. Tal exclusión viene expresada en el artículo 166 del Texto Fundamental, por vía indirecta, cuando atribuye tal iniciativa sólo a los titulares de la iniciativa legislativa incluidos en los dos primeros párrafos del artículo 87, es decir, el Gobierno, el Congreso de los Diputados, el Senado y las Asambleas Legislativas de las Comunidades Autónomas. Esta limitación del objeto de la iniciativa legislativa popular no viene recogida, curiosamente, en la LOILP

A este respecto cabe destacar que el Tribunal Constitucional se expresó claramente en su Sentencia 76/1994, de 14 de marzo, resolviendo un recurso

19. PunSeT Blanco, Ramón: "La iniciativa legislativa en el ordenamiento español" en Revista de Derecho Político, núm.14, 1982, p. 59. 
de amparo interpuesto contra un Acuerdo de la Mesa del Parlamento Vasco que declaraba inadmisible una proposición de ley de iniciativa popular presentada ante el mencionado Parlamento. Los recurrentes instaban, por medio de la iniciativa popular, a que el Parlamento Vasco ejerciera el derecho que le confiere el artículo 166 de la Constitución y solicitara la reforma del Texto Fundamental en el sentido de permitir el acceso a la autodeterminación por parte de los territorios forales.

El fundamento jurídico $5 .^{\circ}$ de esta Sentencia determina que: «En rigor, la proposición de ley presentada por los recurrentes no podía prosperar, ya que se refería a una materia, la reforma de la Constitución española, excluida de la iniciativa popular por el artículo 166 C.E. La prohibición consagrada en este artículo implica, sin necesidad de que venga reiterada en otros preceptos, que en esta materia no cabe ejercer la iniciativa legislativa popular en modo alguno -tampoco indirectamente-; es decir, supone vetar la posibilidad de instar, por medio de una iniciativa legislativa popular, el ejercicio de las facultades de iniciativa que en aquel ámbito se reconocen, en lo que aquí interesa, al Parlamento Vasco. La Constitución ha querido reservar la iniciativa legislativa de reforma constitucional al Gobierno, al Congreso de los Diputados, al Senado y a las Asambleas Legislativas de las Comunidades Autónomas, primando los mecanismos de democracia representativa sobre los de participación directa. Si la Constitución ha prohibido expresamente que la reforma constitucional pueda incoarse como consecuencia del ejercicio de una iniciativa popular, es evidente que servirse de ésta para provocar el ejercicio de una iniciativa parlamentaria, ésta sí legitimada por aquel precepto para iniciar el proceso de reforma, supone contravenir la finalidad perseguida por el constituyente al prever la referida exclusión".

Con la profesora Biglino Campos, se puede concluir este epígrafe afirmando que es menester considerar que los límites impuestos por la Constitución y la LOILP son ya de por sí suficientes (si no excesivos) para garantizar un uso adecuado y no abusivo de la institución. Por ello, la interpretación adecuada debería conducir a restringir dichas limitaciones, ampliando con ello el ámbito de la iniciativa legislativa popular hasta el máximo que permita el ordenamiento jurídico. Operar de otra forma supondría no ya restringir la eficacia de la institución, sino anularla casi por completo ${ }^{20}$.

\section{PROCEDIMIENTO PARA EJERCER LA INICIATIVA}

\section{FORMULACIÓN}

Una vez examinada la titularidad de la iniciativa legislativa popular y su objeto, seguimos los mismos pasos de la LOILP para determinar los requisitos

20. Biglino Campos, Paloma: "La iniciativa...", op. cit., p. 114. 
para su ejercicio. Así, su artículo 3.1 afirma que "la iniciativa popular se ejerce mediante la presentación de proposiciones de ley suscritas por las firmas de, al menos, 500.000 electores autenticadas en la forma que determina la presente Ley". Y el segundo apartado de este mismo artículo señala que el escrito de presentación deberá contener:

a) El texto articulado de la proposición de ley, precedido de una exposición de motivos.

b) Un documento en el que se detallen las razones que aconsejan, a juicio de los firmantes, la tramitación y la aprobación por las Cámaras de la proposición de ley.

c) La relación de los miembros que componen la Comisión Promotora de la iniciativa, con expresión de los datos personales de todos ellos.

Recapitulando, son dos los requisitos que la LOILP establece para presentar una proposición de ley por iniciativa popular: $\left.1 .{ }^{\circ}\right)$ la presentación de un escrito con lós requisitos exigidos en los tres párrafos del segundo apartado del artículo 3 de la Ley, antes transcrito, y $2 .^{\circ}$ ) la firma de un mínimo de 500.000 electores, que se incorpora al procedimiento en un momento no inicial.

Respecto a la exigencia de que el texto de la proposición de ley sea articulado, la LOILP ha optado por el sistema italiano, frente a la posibilidad de la iniciativa simple o inarticulada. El requisito del apartado b) ofrece algún reparo que se expondrá a continuación.

Relevancia especial adquiere la Comisión Promotora, auténtica pieza clave de todo este proceso. Esta Comisión formula la iniciativa ante la Mesa del Congreso, de quien recibe la notificación resolutoria que puede, caso de ser negativa, ser impugnada en amparo ante el Tribunal Constitucional. Cabe señalar, con la profesora Biglino Campos, que no se aclara en la Ley Orgánica ni la naturaleza jurídica de la Comisión Promotora ni el tipo de relación entre la misma y los signatarios de la proposición ${ }^{21}$.

Hay que subrayar que causa cierta perplejidad el requisito señalado en el artículo 3.2.b de la Ley Orgánica. A tenor del mismo, se exige a la Comisión Promotora la presentación de un documento en el que se expresen de forma detallada las razones que aconsejan tramitar ante la Cámara la proposición en que cristaliza la iniciativa. Tal requisito, que no figuraba en la primera redacción del citado texto legal, puede resultar un tanto superfluo. Algunos autores ${ }^{22}$ lo justifican comparándolo con el requisito establecido en el Reglamento del Congreso de los Diputados por el que los proyectos de ley deben ir acompañados, aparte de la exposición de motivos, "de los ante-

21. Ibidem, p. 100.

22. Santamaría Pastor, Juan Alfonso: Articulo 87, op. cit., p. 1263 y Biglino Campos, Paloma: "La iniciativa...", op.cit., p. 117. 
cedentes necesarios para poder pronunciarse sobre ellos". Sin embargo, pese a alguna similitud de ambos requisitos, no se acaba de ver su utilidad, ya que la exposición de motivos (artículo 3.2.a) puede cumplir perfectamente con la finalidad requerida por exigencia del artículo 3.2.b de la LOILP, y, además, el documento señalado en el precepto citado no coincide, en cuanto a su contenido, con los antecedentes previstos en el Reglamento del Congreso para la tramitación de los proyectos de ley.

A la iniciación del procedimiento se refiere el artículo 4 de la LOILP, que fue aprobado sin discusión al no haberse presentado enmienda alguna. Su redacción es del siguiente tenor: "El procedimiento se iniciará mediante la presentación ante la Mesa del Congreso de los Diputados, a través de la Secretaría General del mismo, de la documentación exigida en el artículo anterior. Si la iniciativa se presentara fuera de los períodos de sesión parlamentaria, los plazos comenzarán a computarse en el periodo siguiente a la presentación de dicha documentación".

Como ya se ha indicado anteriormente, la LOILP concede a la Comisión Promotora un relieve especial en estas fases iniciales de presentación de la iniciativa. Es de notar, sin embargo, que la citada ley es muy parca en regular lo referente a dicha Comisión: número mínimo de miembros, naturaleza de la relación jurídica entre ella y los posteriores firmantes, etc.

Tal parquedad puede motivar algunas dudas, por ejemplo, sobre la posibilidad de retirada de firmas, y, si ello es posible, hasta qué momento puede producirse tal retirada; o si la Comisión Promotora puede, a su vez, retirar la iniciativa, y si para ello se requiere el asentimiento de los firmantes.

Nada de ello obtiene respuesta legalmente prevista. Por ello, las diversas soluciones sólo podrán ser fruto de elaboración doctrinal y, en su caso, jurisprudencial.

La primera pregunta que cabe hacerse es ante quién hay que plantear la posible retirada de la firma. Evidentemente, sólo podrá ser ante la Comisión Promotora o ante la Mesa del Congreso. Ambas soluciones poseen argumentos a favor y en contra. No se entiende que pueda ser ante la Comisión Promotora, toda vez que el procedimiento, ya en marcha, depende de la Mesa de la Cámara al haber admitido ésta la proposición, pues es después de tal admisión cuando se produce la recogida de firmas. Tendrá que ser ante dicho órgano de gobierno del Congreso, aunque sólo sea en virtud de la genérica justificación del derecho de petición que asiste a todo ciudadano.

El firmante podrá retirar su firma antes de iniciarse la tramitación parlamentaria o, para ser más exactos, antes de que se incluya en el orden del día del Pleno para su toma en consideración. Parece la solución más acorde con el artículo 129 del Reglamento del Congreso, que indica que la iniciativa de la retirada de una proposición de ley por su proponente tiene pleno efecto si se produce antes del acuerdo de la toma en consideración. Una vez que ésta se ha adoptado, la retirada sólo puede efectuarse por el acuerdo del Pleno de la Cámara. 
Visto lo relativo a la posible retirada de las firmas por sus signatarios, cabe detenerse ahora en la eventual retirada de la proposición como tal. Respecto a las diversas cuestiones que puede plantear la retirada de la proposición por parte de la Comisión Promotora parece oportuno distinguir los diversos momentos en que tal retirada puede producirse para deducir sus consecuencias.

Por lo pronto, hay que tener en cuenta que la formulación de la iniciativa se produce antes de que se formalice el proceso de recogida y acreditación de firmas, por lo que, hasta que ésta se produzca, nada empece a que la Comisión Promotora retire la propuesta. Ella sola es la proponente hasta ese momento, y, por tanto, goza de plena libertad para echarse atrás. Esa es la línea del artículo 6.3 de la LOILP, al permitir a la Comisión Promotora retirar la iniciativa cuando el Tribunal Constitucional ha resuelto, en amparo, que hay irregularidades que afectan a determinados preceptos de la proposición. Hay que recordar que ese recurso de amparo se plantea cuando la Mesa del Congreso ha denegado la admisión a trámite de la iniciativa, lo cual se produce antes de la recogida y acreditación de firmas.

Admitida a trámite la iniciativa, y abierto el proceso de recogida de firmas, puede plantearse la posible retirada de tal iniciativa por su Comisión Promotora. Tampoco habría especial dificultad en este caso. Se trataría de un desistimiento por la Comisión Promotora, sin mayores consecuencias.

Una vez producido el trámite de la toma en consideración, la situación queda notablemente modificada, por lo que habría que traer de nuevo a colación el artículo 129 del Reglamento del Congreso, que acaba de ser citado.

Sin embargo, de lege ferenda, puede aventurarse otra solución. Y esa solución pasa por la eliminación del trámite de la toma en consideración, de una parte, y en la posibilidad de retirada de este tipo de proposiciones de ley, fruto de la iniciativa legislativa popular, tal como ocurre con los proyectos de ley, que hoy por hoy tienen requisitos distintos a tenor de los artículos $128 \mathrm{y}$ 129 del Reglamento del Congreso de los Diputados.

El tratamiento, en cuanto al procedimiento, de las proposiciones de ley fruto de la iniciativa legislativa popular produce -como ya se ha dicho antesque la retirada de las mismas sólo pueda realizarse, a petición de su proponente, antes del acuerdo de la toma en consideración, siendo necesario el acuerdo del Pleno de la Cámara para hacerlo después (art. 129) Sin embargo, a tenor del artículo 128, el Gobierno puede retirar un proyecto de ley - que es otra iniciativa legislativa exógena a las Cortes- en cualquier momento de su tramitación mientras no recaiga acuerdo final del Pleno. Parece que éste podría ser el tratamiento adecuado respecto a la iniciativa legislativa popular, en lo referente a su posible retirada.

Parece oportuno afirmar que el respeto a la voluntad popular manifestada a través de este instrumento de participación directa merecería un trato más deferente, al menos equiparable con el dado al Gobierno.

Las cautelas respecto a las proposiciones promovidas en el seno de la Cámara misma tienen una motivación debida, en definitiva, a su carácter endó- 
geno. Pero no tiene el mismo sentido mantener tal actitud respecto a esas otras proposiciones que han signado al menos quinientos mil electores. A efectos de su posible retirada, deberían equipararse a los proyectos de ley y poder efectuar la misma mientras no recaiga acuerdo final de la Cámara. Esta situación podría darse, por ejemplo, en el caso de que la Comisión Promotora observara que, en sede parlamentaria, se han introducido, a lo largo de la tramitación, modificaciones que han desvirtuado el sentido original de la iniciativa.

A esta situación general de desigualdad de trato respecto a la iniciativa popular, viene a sumarse, en este apartado, el hecho de que las iniciativas procedentes de las Asambleas Legislativas de las Comunidades Autónomas pueden ser tramitadas o por el Gobierno como proyectos de ley, en cuyo caso gozan de sus ventajas, o como proposiciones de ley, pero, en este caso el artículo 87.2 de la Constitución posibilita a dichas Asambleas Legislativas de las Comunidades Autónomas el delegar ante el Congreso un máximo de tres miembros de la Asamblea para que defiendan la iniciativa. Opción no reconocida a la Comisión Promotora de la iniciativa legislativa popular, que, por así decirlo, "abandona" su propuesta sin que, una vez presentada, pueda matizar o aportar nada en su defensa. A partir de ahí, la proposición queda a merced de las Cámaras, con el ya citado peligro, de que la misma pueda quedar desvirtuada.

\section{ADMISIÓN A TRÁMITE}

La regulación del trámite de admisión de la iniciativa legislativa popular, que es, sin duda, la parte del procedimiento que suscita más interés y plantea más dificultades, ha sido realizada con minuciosidad por la LOILP, tal como ha señalado la profesora Biglino Campos ${ }^{23}$.

El artículo 5 de la LOILP establece:

1. "La Mesa del Congreso de los Diputados examinará la documentación remitida y se pronunciará en el plazo de quince días sobre su admisibilidad.

2. Son causas de inadmisión de la proposición:

“a) Que tenga por objeto alguna de las materias excluidas de la iniciativa popular por el articulo $2 .^{\circ}$.

b) Que no se hayan cumplimentado los requisitos del artículo $3 .^{\circ}$. No obstante, si se tratase de defecto subsanable, la Mesa del Congreso de los Diputados lo comunicará a la Comisión Promotora para que proceda, en su caso, a la subsanación en el plazo de un mes.

c) El hecho de que el texto de la proposición verse sobre materias diversas carentes de homogeneidad entre si.

23. Biglino Campos, P.: Los vicios en el procedimiento legislativo, Centro de Estudios Constitucionales, Madrid, 1991, p. 86. 
d) La previa existencia en el Congreso o en el Senado de un proyecto o proposición de ley que verse sobre el mismo objeto de la iniciativa popular y que esté, cuando ésta se presenta, en el trámite de enmiendas u otro más avanzado.

e) El becho de que sea reproducción de otra iniciativa popular de contenido igual o sustancialmente equivalente presentada durante la legislatura en curso.

f) La previa existencia de una proposición no de ley aprobada por una Cámara que verse sobre la materia objeto de la iniciativa popular..

3. La resolución de la Mesa de la Cámara se notificará a la Comisión Promotora y se publicará de acuerdo con lo que al efecto disponga el Reglamento del Congreso de los Diputados.

Como puede apreciarse, es en la Mesa del Congreso en quien recae el protagonismo en estas primeras fases del procedimiento de tramitación de la iniciativa legislativa popular. En la iniciación del mismo se limita a ser receptora de la iniciativa. En la admisión a trámite, ejerce una labor calificadora, resolviendo sobre la admisión de la iniciativa. Así, el artículo 127 del Reglamento del Congreso de los Diputados establece que las proposiciones de iniciativa legislativa popular "serán examinadas por la Mesa del Congreso a efectos de verificar el cumplimiento de los requisitos legalmente establecidos".

La primera cuestión a examinar, y que ha sido, sin duda alguna, la más debatida doctrinalmente, es el elenco de las causas de inadmisión de la proposición, que enumera el segundo párrafo del transcrito artículo 5. Cabe repasarlas, y detenerse, principalmente, en aquéllas que ofrezcan un mayor interés.

Pocos problemas plantea la inadmisión por el hecho de que la iniciativa tenga contenidos que le son expresamente vetados, apartado a) del párrafo 2. En cualquier caso, se trata de las materias enumeradas en el artículo 87.3, último inciso, de la Constitución, y en el artículo 2 de la LOILP Ambas enumeraciones coinciden, aunque la Ley Orgánica añade dos materias más respecto a la relación constitucional, tal como ya ha sido expuesto: las mencionadas en los artículos 131 -los proyectos de planificación económica general, cuya elaboración corresponde al Gobierno-y 134.1 -los Presupuestos Generales del Estado- cuya elaboración también es competencia exclusiva del Gobierno. Pero tampoco la LOILP, al igual que la Constitución, enumera como materia excluida, la iniciativa de reforma constitucional. Como ya se ha dicho, es el artículo 166 del Texto Fundamental quien realiza implícitamente dicha exclusión.

El apartado b) contiene una causa formal de inadmisión: la falta de cumplimiento de los requisitos exigidos en el artículo 3 de la LOILP. Aunque ese mismo artículo añade la posibilidad de subsanación en el plazo de un mes, cuando el defecto sea subsanable. Como el citado artículo 3 ya ha sido comentado, basta aquí recordar que el escrito de presentación debe contener como requisitos: el texto articulado de la proposición de ley, precedido de una exposición de motivos, un documento en el que se detallan las razones de los 
firmantes para que las Cámaras la tramiten y aprueben, y la relación de miembros que componen la Comisión Promotora de la iniciativa con sus datos personales.

De lo expuesto hasta aquí, se deduce que la causa de inadmisión de la iniciativa del artículo 5.2. a) de la LOILP es de naturaleza material, mientras que la del apartado b) es de origen formal. Las cuatro causas restantes son de menor nitidez y fueron motivo de polémica al debatirse la LOILP, especialmente la enunciada en el apartado c). En virtud del mismo se determina como causa de inadmisión el que el texto de la proposición verse sobre materias diversas carentes de homogeneidad entre sí. El proyecto de ley se refería a "carencia de unidad sustantiva" y sobre el alcance de esta expresión se planteó la polémica.

Lapuerta Quintero, del Grupo Parlamentario Popular, expresó su oposición a esa redacción del proyecto en los siguientes términos: "Examinemos nuestra enmienda al artículo 5.2. c), que menciona la carencia de unidad sustantiva del texto de la proposición como causa de inadmisión de la iniciativa, y cuya supresión proponemos. Los restantes apartados tienen misiones claras. Así, el punto a) excluye las materias vedadas por la Constitución; el b) establece la vinculación a unos requisitos formales mínimos y subsanables ... Pero ¿cuál es la razón que informa el apartado que nos ocupa? ¿por qué se impone este requisito a la iniciativa popular en concreto?". Y añadió: "En primer lugar su redacción es desafortunada. ¿Qué quiere decir la carencia de unidad sustantiva?. Puede referirse a la regulación de un tema de forma desconexa, tocando aspectos del mismo, pero sin abarcarlo sistemáticamente en su totalidad y sin dotarlo de una unidad sustancial. Puede referirse a la imposición de que la proposición abarque dos o más materias heterogéneas. Puede ser que se pretenda recoger esta última acepción, pero no debemos olvidar que una cosa es lo que se quiso decir y otra muy distinta lo que se ha dicho".

Continuó su reflexión diciendo: "Por tanto, hubiera sido preferible decir "la diversidad temática" en lugar de "la unidad sustantiva". Pero aun con este segundo significado, el requisito no es admisible. Su única razón es la de ignorancia del ciudadano que va a presentar la proposición de ley que intenta regular a la vez temas sin ninguna relación entre sí. Y no es así. La proposición va a ser elaborada por asesores jurídicos, y aunque formularon una mala proposición y se consiguieron las 500.000 firmas, existe, si la ley es válida en todo lo demás, todo un procedimiento de tramitación de la proposición que serviría para pulirla y mejorarla. Lo que no se puede aceptar es limitar un derecho constitucional porque se tema que se va a ejercitar de una forma poco técnica". Y concluyó afirmando: "diré que no existe ninguna razón de peso para no aceptar nuestra enmienda y, sin embargo, dada la interconexión que entre las distintas materias existe, no hacerlo supondría una fortísima dosis de discrecionalidad por parte de la Mesa del Congreso; discrecionalidad que, si bien es admisible en la Administración, debe quedar desterrada de nuestro 
poder, el legislativo, siendo lo más inaceptable que esta discrecionalidad recortase un derecho constitucional, ${ }^{24}$.

Por el Grupo Parlamentario Vasco, el diputado Vizcaya Retama pretendió también la supresión de la frase "unidad sustantiva", porque con ella "se viene de algún modo a vulnerar el artículo 87.3 de la Constitución. Formalmente es cierto que se puede exigir una unidad de contenido material en una proposición de este tipo, pero este requisito que no deja de ser meramente formal, no puede constituirse en obstáculo de fondo para la presentación de la iniciativa legislativa popular, ${ }^{25}$.

El diputado Fernando Pérez Royo era partidario de la supresión del apartado en cuestión y del siguiente; "por entender fundamentalmente que son requisitos sobreañadidos, porque no están en la Constitución ${ }^{26}$.

Por fin, se redactó de nuevo el texto legal; y se incorporó la fórmula definitiva.

Por su parte, la doctrina también ha criticado el mencionado requisito, incluso con su definitiva redacción. Así, el profesor Santamaría Pastor ha afirmado que ano parece que pueda considerarse objetivamente como un motivo de rechazo de la iniciativa. Aparte de lo ambiguo del concepto de bomogeneidad, este requisito, aplicado a la iniciativa del Gobierno, llevaría indefectiblemente a rechazar todos los Proyectos de Ley de Presupuestos Generales del Estado. No hay razones para exigir un mayor grado de coherencia interna a las iniciativas de origen popular que a las gubernamentales o parlamentarias ${ }^{27}$.

Al hilo del comentario transcrito, no será ocioso volver a repetir algo que ha venido señalándose en apartados anteriores. $Y$ es la discriminación sufrida por la iniciativa popular, que viene a resultar la cenicienta de todas las iniciativas legislativas, pese a la profesión de fe que nuestra Constitución realiza en favor de la soberanía del pueblo.

Puede terminarse este comentario, haciendo, con la profesora Biglino Campos, una valoración matizada de este precepto: "La disposición puede cumplir un eficaz papel positivo al evitar que los signatarios de la iniciativa, para apoyar sólo un aspecto de la proposición, se vean obligados a aceptar temas que, sin embargo, no son de su agrado. Pero al tiempo constituye, sin duda alguna, un peligro para los promotores de la iniciativa, en cuanto que los criterios para establecer si una proposición es internamente homogénea no son claramente determinables y puede fácilmente encubrir resoluciones discrecionales, tomadas en virtud de criterios políticos ${ }^{28}$.

24. Diario de Sesiones del Congreso de los Diputados, núm. 79 , sesión de 29 de noviembre de 1983.

25. Ibidem.

26. Ibidem.

27. Santamaría Pastor, J.A.: Artículo 87, op. cit, p. 1264.

28. Biguno CAMPOS, P.: "La iniciativa legislativa popular", op. cit, p. 117. 
Los apartados d), e) y f) del párrafo segundo del arriba transcrito artículo 5 de la LOILP contienen otros tantos motivos de inadmisión basados en armonizar el ejercicio de la iniciativa legislativa popular con la tarea propia de las Cámaras, como órganos del Poder Legislativo. Tampoco su existencia ha estado exenta de polémicas, y es que, en el fondo, y una vez más, habrá que insistir en ello: el constituyente y el legislador han sido cicateros en lo que a las fórmulas de democracia directa se refiere.

La causa de inadmisión prevista en el apartado d) del artículo 5.2 plantea varias cuestiones sobre la base de lo que anteriormente se acaba de expresar. Porque, si el último inciso del apartado en cuestión apenas produce dificultad alguna de interpretación -el proyecto o proposición de ley previo a la iniciativa popular está en trámite de enmiendas u otro posterior- no puede decirse igual de la exigencia de que el objeto de la iniciativa popular no verse sobre el mismo objeto que un proyecto o proposición previamente presentados en el Congreso. ¿Qué quiere decir identidad de objeto?, ¿no hay grados y matices diversos en una identidad?, ¿no existen aspectos diversos dentro de un mismo objeto? y, sobre todo, ¿no parece conceder la LOILP, una vez más, una peligrosa discrecionalidad a la Mesa del Congreso de los Diputados?.

Cabría responder a ello que siempre puede la Comisión Promotora interponer el correspondiente recurso de amparo al que le faculta el artículo siguiente. Sin embargo, atinadamente apunta Santamaría Pastor: «La conclusión, por dura que parezca, es obvia: esta causa de inadmisión es inconstitucional, además de prestarse a maniobras fácilmente impeditivas de toda iniciativa popular (basta con que el Gobierno tenga conocimiento de los proyectos para formularla para que la aborte esbozando un proyecto de ley sobre la misma materia, aunque de contenido diverso), ${ }^{29}$.

En todo caso no deja de ser curioso que vuelva a darse preferencia a la tarea del órgano de representación popular -el Congreso- que a la iniciativa popular misma, pero, sobre todo, resulta cuanto menos chocante, una vez más, el margen de discrecionalidad de la Mesa del Congreso en lo que a la tramitación de la iniciativa se refiere.

En estrecha relación con la causa de inadmisión prevista en el artículo 5.2. d) se encuentra la del párrafo siguiente, el e). En su virtud, la inadmisión se produce por la coincidencia de la iniciativa propuesta con otra del mismo origen presentada durante la misma legislatura. Sin embargo, esta causa parece más armónica y de mayor fundamento que la anteriormente examinada. Porque bien podría ocurrir que ante una iniciativa que no prospera, ésta se reprodujera una y otra vez entorpeciendo la propia labor de la

29. Santamaría Pastor, J.A.: Artículo 87, op. cit, p. 1.264. Apunta la inconstitucionalidad por entender que el apartado citado colisiona con el artículo 89.1 de la Constitución. Opinión no compartida por Biglino Campos, P.:"La iniciativa legislativa popular", op. cit, p.119, al entender que el apartado de la LOILP desarrolla el mandato constitucional del artículo 87.3. 
Cámara. Todo ello no es incompatible con reconocer la ambigüedad del precepto - $\rightarrow$ contenido igual o sustancialmente equivalente - y la consiguiente discrecionalidad de que puede disponer otra vez más la Mesa del Congreso de los Diputados.

Opinión más severa merece la causa de inadmisión de la proposición de iniciativa legislativa popular contemplada en el artículo 5.2. f: "la previa existencia de una proposición no de ley aprobada por una Cámara que verse sobre la materia objeto de la iniciativa populam. De entre las más atinadas y severas críticas, puede destacarse la del profesor Santamaría Pastor, que compartimos en todos y cada uno de sus términos: “... es la causa de inadmisión menos justificada de todas: basta que haya sido aprobada una proposición no de ley (que no tiene carácter normativo) y que verse sobre la misma materia (ni siquiera que sea de sentido o contenido idéntico al de la iniciativa) 30 .

A la crítica de Santamaría Pastor aún se puede añadir una apostilla de tono menor respecto al precepto citado, y es que cabría pensar el absurdo que supone que la proposición no de ley coincidente hubiera sido aprobada en el Senado, teniendo en cuenta que la iniciativa popular se tramita en el Congreso, cuya Mesa resuelve sobre su admisión.

También durante la tramitación parlamentaria de la LOILP se solicitó la supresión de los apartados d), e) y f) del artículo 5.2. El diputado Vizcaya Retana dudó de la constitucionalidad del apartado d) y se quejó del trato discriminatorio de las diferentes modalidades de la iniciativa legislativa, refiriéndose también a los otros requisitos: «No parece sino que, de algún modo, ustedes tuvieran cierto temor a la iniciativa legislativa popular, porque han rodeado su admisión de una serie de requisitos tales que no exigen ustedes a los Grupos Parlamentarios, que por su dedicación, su profesionalidad, por su conocimiento de la vida legislativa se les debería exigir con mucho más razón que a una iniciativa popular ... En todo caso ustedes sabrán que reglamentariamente hay una solución, que es que se acumule la tramitación ... Estas dos causas de inadmisibilidad, las que se indican en los apartados d) y e) no tienen justificación ninguna más que de temor a lo que ustedes pueden considerar presión popular a la Cámara, que yo considero ejercicio de un sano derecho democrático, que es el que resume el artículo $87,3^{31}$.

\section{RECURSO CONTRA LA NO ADMISIÓN}

El artículo 6 de la LOILP establece la posibilidad de interponer el recurso de amparo ante el Tribunal Constitucional. En concreto dice así:

30. Santamaría Pastor, J.A.: Artículo 87, op. cit, p. 1265.

31. Diario de Sesiones del Congreso de los Diputados, núm. 79, sesión de 29 de noviembre de 1983. 
"1. Contra la decisión de la Mesa del Congreso de no admitir la proposición de Ley, la Comisión Promotora podrá interponer ante el Tribunal Constitucional recurso de amparo, que se tramitará de conformidad con lo previsto en el Título III de la Ley Orgánica 2/1979, de 3 de octubre, del Tribunal Constitucional.

2. Si el Tribunal decidiera que la proposición no incurre en alguna de las causas de inadmisión previstas en el apartado 2 del artículo 5, el procedimiento seguirá su curso.

3. Si el Tribunal decidiera que la irregularidad afecta a determinados preceptos de la proposición, la Mesa del Congreso lo comunicará a sus promotores, a fin de que éstos manifiesten si desean retirar la iniciativa o mantenerla una vez que bayan efectuado las modificaciones correspondientes".

La Ley Orgánica del Tribunal Constitucional establece, en su artículo 41, la protección del recurso de amparo ante dicho Tribunal, para proteger los derechos y libertades reconocidos en los artículos 14 a 29 de la Constitución y para la objeción de conciencia reconocida en el artículo 30.2, respecto de las violaciones de los mismos producidas por disposiciones, actos jurídicos o simple vía de hecho de los poderes públicos en cualquiera de sus modalidades. Y el artículo 42 de la misma Ley Orgánica, concretando esta posibilidad, afirma que las decisiones o actos sin valor de Ley, emanados de las Cortes o de cualquiera de sus órganos que violen los derechos y libertades susceptibles de amparo constitucional, podrán ser recurridos dentro del plazo de tres meses desde que, con arreglo a las normas internas de las Cámaras, sean firmes. A esta cuestión se había hecho anterior referencia que, ahora, se completa.

La no admisión de la iniciativa legislativa popular por parte de la Mesa del Congreso es una decisión o acto sin valor de ley emanada por un órgano de las Cortes, la Mesa del Congreso de los Diputados, órgano rector de dicha Cámara, a tenor de la literalidad del artículo 30.1 del Reglamento de la misma.

Evidentemente, el derecho aquí violado es el reconocido en el artículo 23.1 de la Constitución, por el que se declara como derecho fundamental el de participación en los asuntos públicos.

Cabría preguntarse, con el profesor Santamaría Pastor, sobre la necesidad de que el artículo 6 de la LOILP haya establecido este recurso de amparo específicamente contra la resolución denegatoria de la Mesa del Congreso: «un precepto acertado, aunque en cierta manera superfluo, por cuanto el recurso de amparo hubiera sido admisible por infracción del art. 23 de la Constitución ${ }^{32}$.

Cierta es la posible duplicidad o mejor aún, su posible carácter superfluo, pero no hay que olvidar que aunque la intervención del Tribunal Constitucional se produce ante la posible vulneración del artículo 23.1, encuentra su marco legal en el artículo 42 de su Ley Orgánica que le concede la facultad 
de controlar decisiones o actos sin valor de ley emanados de las Cortes o de sus órganos.

La intervención del Tribunal Constitucional decidiendo sobre las causas de inadmisión previstas en el artículo 5.2 de la LOILP produjo el rechazo de un sector del Congreso cuando se debatió dicha Ley. Para ese sector, el Tribunal Constitucional sólo podía definirse sobre las causas de inadmisibilidad previstas en la Constitución, pero no sobre las previstas en la Ley Orgánica.

En concreto, el diputado Fernando Pérez Royo afrimó: «Quiero decir, en todo caso, que el bloque de materias que la Constitución elimina de la iniciativa legislativa popular se refiere a la del artículo 87.3, que en su mayor parte, son materias de carácter esencialmente legislativo, más la materia presupuestaria del artículo 134.1, más la materia de planificación. Únicamente en estas materias entendemos que el Tribunal Constitucional tiene competencia para pronunciarse y para, en virtud de la vulneración de estos preceptos constitucionales, decretar la inadmisibilidad de la iniciativa legislativa popular ${ }^{33}$.

El profesor García Morillo defiende la oportunidad de la regulación legal: "Por consiguiente, cuando no se trate de actos de personal o administración no será aplicable, contra las resoluciones o actos de las Cámaras legislativas o sus órganos de gobierno, el recurso contencioso-administrativo pero sí podrá requerirse el amparo del TC por la vía prevista en el artículo 42 de su ley reguladora ${ }^{34}$.

La legitimación para acudir en amparo ante el Tribunal Constitucional corresponde a la Comisión Promotora, a tenor del artículo 6.1 de la LOILP, quien puede ejercer dicha legitimación en el plazo de tres meses desde que la decisión de inadmisión de la Mesa del Congreso sea firme. Habrá que entender que tal momento se produce a partir de la publicación de la resolución denegatoria y no a partir de la simple notificación a la Comisión Promotora. Parece que ésta la interpretación correcta del artículo 5.3 de la Ley Orgánica. La publicación de la iniciativa y la resolución de la Mesa deberán hacerse en el Boletín Oficial de las Cortes Generales, Sección Congreso de los Diputados, a tenor de lo establecido en los artículos 95, 126 y 127 del Reglamento del Congreso.

La interpretación aceptada se ve reforzada, además, por la literalidad del artículo 42 de la Ley Orgánica del Tribunal Constitucional, que concede - para la imposición del recurso de amparo- el plazo de tres meses, a contar desde que los actos o decisiones sin valor de ley de las Cortes sean firmes, de acuerdo con las normas internas de las Cámaras. La exigencia de la firmeza del acto hace opinar en favor de contar el plazo desde la publicación dicho acto.

33. PÉREz Royo: Diario de Sesiones del Congreso de los Diputados, núm. 79, sesión de 29 de noviembre de 1983.

34. García MORILO, J.: La protección judicial de los derechos fundamentales, Tirant lo Blanch, Valencia, 1994, p. 185. 
Los párrafos 2 y 3 del artículo 6 de la LOILP recogen los efectos de la sentencia del Tribunal Constitucional ante el recurso de amparo planteado por la Comisión Promotora a causa de la inadmisión de la proposición por parte de la Mesa del Congreso. Si la proposición no incurre en causa de inadmisión, el procedimiento seguirá su curso, procediéndose a la recogida de firmas y su acreditación. Si la irregularidad afecta a determinados preceptos de la proposición, los promotores decidirán entre retirar la iniciativa o mantenerla, con las oportunas modificaciones.

Evidentemente hay una tercera posibilidad que la Ley Orgánica debe dar por sobreentendida, y es que el Tribunal aprecie la razón de la Mesa, al entender que la proposición, o su contenido esencial, es inadmisible, con lo que se da por definitivamente rechazada.

\section{RECOGIDA Y ACREDITACIÓN DE FIRMAS}

Pese a que es el aspecto del procedimiento más largamente tratado en la LOILP, su regulación ofrece, sin embargo, pocas dificultades dignas de consideración. Los artículos 7 a 12 de la Ley se dedican a esta fase. Vale la pena, en todo caso, detenernos en algunos aspectos de su contenido.

En primer lugar, cabe destacar el papel que asume la Junta Electoral Central "que garantizará la regularidad del procedimiento de recogida de firmas", según expresa al apartado 1 del artículo 7. La tarea de la Junta comenzará una vez que la Mesa del Congreso le comunique que la proposición ha sido admitida.

La Junta Electoral Central notifica a la Comisión Promotora de la iniciativa el hecho de su admisión para que se proceda por ésta a la correspondiente recogida de firmas. Esta disposición del artículo 7.2 de la LOILP supone la existencia de otra notificación de la admisión distinta de la que la Mesa del Congreso debe realizar a la citada Comisión para informarle de que su iniciativa ha sido aceptada por el órgano rector de la Cámara. El escaso interés que el artículo produjo a la hora de su aprobación, y la subsiguiente ausencia de debate, no ayudan a aclarar el contenido o, más bien, el alcance de esa notificación de la Junta Electoral.

El hecho es que parece que nos encontramos con la existencia de tres comunicaciones o notificaciones distintas. Por la primera, la Mesa del Congreso comunica a la Comisión Promotora el hecho de la admisión a trámite de la iniciativa. Por la segunda, la Mesa comunica a la Junta Electoral Central la existencia de una proposición de ley, fruto de la iniciativa legislativa popular, que ha sido admitida a trámite por dicha Mesa, y que ahora comienza el trámite de recogida y acreditación de firmas que la Junta debe controlar. En la tercera comunicación, prevista en el citado artículo 7.2, y, muy posiblemente, superflua, la Junta Electoral Central notifica a la Comisión Promotora la admisión a trámite de su iniciativa, para que ésta proceda a recoger las quinientas 
mil firmas constitucionalmente exigidas para que la tal iniciativa continúe su tramitación parlamentaria. Parece que con las dos primeras notificaciones mencionadas sería suficiente.

La interpretación más segura es pensar que la notificación oficial de la admisión de la proposición de la iniciativa corresponde, como no puede ser de otra manera, a la Mesa del Congreso, quien decide sobre tal admisión y la notifica a la Comisión Promotora. Recordemos que, precisamente, cuando tal decisión es firme es cuando - caso de inadmisión- puede ser recurrida en amparo. La Junta Electoral lo que hace es comunicar a la Comisión que ha recibido notificación -oficial- de la Mesa del Congreso, y que comienza el proceso de recogida de firmas, que, dado su paralelismo con la actividad electoral, la Junta vigila.

La Comisión Promotora tiene un plazo de seis meses, a contar desde la notificación de la Junta, para proceder a la recogida de firmas, plazo que puede prorrogarse hasta nueve meses si hay causas de fuerza mayor. Causas que, a tenor del artículo 7.3 de la LOILP, ha de examinar la Mesa del Congreso. Agotado el plazo sin la entrega de firmas -lo que se hace ante las Juntas Electorales Provinciales- caduca la iniciativa.

En el Proyecto del Gobierno figuraba sólo el plazo de seis meses para la recogida de firmas. El Grupo Vasco, por enmienda defendida por el diputado Vizcaya Retana, propuso la prórroga de tres meses, a discreción de la Junta Electoral Central ante la existencia de fuerza mayor. La enmienda fue aceptada en la parte correspondiente a la prórroga y su plazo, y se modificó, aparte de algún detalle gramatical, en lo referente al ente que debe conceder dicha prórroga, en favor de la Mesa del Congreso.

La solución, pese a todas las ventajas que pueda tener, ofrece también algunos puntos que, cuando menos, llaman la atención. En primer lugar, el hecho mismo de la prórroga. Si tan dificultoso puede ser llegar a reunir las 500.000 firmas, y ello es indudable, cabe preguntarse si no hubiera sido mejor establecer un plazo único más largo -los nueve meses- con carácter máximo o preclusivo, en línea parecida a la que sostenía el Proyecto. Porque ello no quiere decir, obviamente, que tenga que agotarse tal plazo. Por un lado, hay que pensar que la Comisión Promotora tendrá que haber hecho una exploración de posibles firmantes, y que no va a empezar de cero desde la aceptación de la proposición por parte de la Mesa del Congreso. Esa unificación con carácter de máximo eliminaría la posible discrecionalidad y resulta suficiente, incluso, para disuadir posibles iniciativas poco ponderadas, lo que no resulta fácil que ocurra, pero no por ello imposible.

Por otro lado, también resulta de dudosa oportunidad la atribución a la Mesa del Congreso de la concesión de la prórroga. Cabe plantearse, si, como figuraba en la enmienda, no sería mejor que tal facultad hubiera recaído en la Junta Electoral Central. De nuevo nos encontramos con un protagonismo discrecional del órgano de gobierno de la Cámara Baja que puede resultar excesivo. La Junta, incluso, podría contar con datos técnicos que pueden servir para apreciar con más rigor la necesidad de tal prórroga. 
Las características de los pliegos de recogida de firmas se regulan en el artículo 8 de la LOILP, estableciendo su tercer párrafo la intervención de la Junta Electoral Central a la hora de sellar y numerar los pliegos que reproducirán, además, el texto íntegro de la proposición, a tenor del párrafo primero del precepto citado.

La autențicación de firmas queda regulada en el artículo 9 de la Ley Orgánica, que dispone que cada firma debe ir acompañada de nombre, apellidos, número del DNI y municipio en que el firmante se halla censado. La autenticación, que debe indicar su fecha, corresponde a un notario, o a un secretario judicial, o a un secretario municipal del lugar en que el firmante esté censado. Se admite la autenticación colectiva incluyendo, en este caso, el número de firmas que corresponde a cada pliego.

Este artículo 9 modificó su redacción del párrafo primero, al aceptarse una enmienda del Grupo Popular en el sentido de que fuera innecesaria el dato -junto a la firma- del lugar y fecha de nacimiento del elector. En nombre del citado Grupo, el diputado Lapuerta Quintero manifestó: "proponemos la supresión, en los datos personales que deban acompañar a la firma, del lugar y fecha del nacimiento", ya que "el que la persona tenga veinte o sesenta años es absolutamente irrelevante ${ }^{35}$.

El artículo 10 prevé la posibilidad de la existencia de fedatarios especiales para autenticar las firmas. Esos fedatarios han de ser designados por la Comisión Promotora y jurar o prometer el correcto desempeño de su función ante las Juntas Electorales Provinciales, incurriendo, en caso de falsedad, en las responsabilidades legalmente previstas. La designación de fedatarios debe recaer en ciudadanos españoles mayores de edad, en pleno ejercicio de sus derechos y que carezcan de antecedentes penales.

Una vez recogidas las firmas, se envían los pliegos correspondientes a las Juntas Electorales Provinciales, que efectúan una primera labor de comprobación y recuento, que no puede exceder de quince días. Concluida la tarea, envían los pliegos a la Junta Electoral Central, manteniendo las Provinciales un carácter auxiliar de cara a la acreditación de firmas.

La Junta Electoral Central procede a la comprobación y recuento definitivos. Comprobación que, de cumplirse los requisitos legales, termina con el envío por la Junta a la Mesa del Congreso de la correspondiente certificación acreditativa.

Es en esta fase del procedimiento cuando se perfecciona la verdadera iniciativa popular, materializada en esas 500.000 firmas que suscriben la propuesta. Las fases anteriores sirven de preparación para que la petición popular se produzca. Ahora, el Congreso de los Diputados continuará la tramitación, pero tiene ya enfrente quinientas mil adhesiones a una solicitud

35. Diario de Sesiones del Congreso de los Diputados, núm. 79, sesión de 29 de noviembre de 1983. 
legislativa, y ya debe comenzar, de manera obligatoria, un procedimiento. Debe iniciarse así la tramitación parlamentaria de la iniciativa legislativa popular.

\section{TRAMITACIÓN PARLAMENTARIA}

Muy posiblemente es esta la fase del procedimiento que más controversias y polémicas ha generado, debido, en gran manera, a la necesidad de la "toma en consideración" de la proposición por parte del Congreso. Como ya con anterioridad el tema ha sido desarrollado, basten ahora unas breves reflexiones sobre este punto.

Para seguir el orden lógico, bueno será transcribir el artículo 13 de la LOILP, que sobriamente desarrolla la cuestión de la tramitación parlamentaria de la iniciativa legislativa popular. El último momento de la fase anterior consistía en la comunicación de la Junta Electoral Central a la Mesa del Congreso de la certificación acreditativa del número de firmas válidas. Pues bien, el artículo 13 establece:

"1. Recibida la notificación que acredite haberse reunido el nümero de firmas exigido, la Mesa ordenará la publicación de la proposición, que quedará en condiciones de ser incluida en el orden del día del Pleno para su toma en consideración.

2. El debate se iniciará mediante la lectura del documento a que se refiere el articulo 3, apartado 2 b), de la presente Ley Orgánica" (este documento citado en el párrafo 2 es aquél en el que detallaban las razones de los firmantes para que las Cámaras tramitaran la proposición de ley).

Por razón de conexión temática, hay que volver a hacer referencia a la cuestión de la toma en consideración por parte del Congreso. La crítica contra el requisito de someter las proposiciones de ley fruto de la iniciativa popular al trámite de la toma en consideración no sólo ha tenido alcance doctrinal - Santamaría Pastor, De Esteban y López Guerra, entre otros- sino que el Proyecto de Ley de la LOILP la excluía. Fue la Ponencia quien la introdujo, contra la opinión de varios grupos parlamentarios, el Popular por ejemplo, que pretendía, mediante voto particular, mantener la primitiva redacción del proyecto redactado por el Gobierno.

Lapuerta Quintero, en representación de ese Grupo, lo expresó así: «La iniciativa legislativa popular da lugar a proposiciones que, por un lado, tienen la virtud de haber nacido fuera de la Cámara, y, por otro, están avaladas por, al menos, quinientas mil firmas. Estas dos circunstancias conllevan a nuestro entender, la consiguiente omisión del trámite de toma en consideración ${ }^{36}$.

36. . Diario de Sesiones del Congreso de los Diputados, núm. 79, sesión de 29 de noviembre de 1983. 
También se planteó en el Congreso de los Diputados -Pérez Royo- la posibilidad de que la Comisión Promotora de la iniciativa legislativa popular pudiera personarse en la Cámara "para exponer personalmente, de viva voz, los motivos que fundamentan o que avalan dicha iniciativa. Se trata, en definitiva, de reproducir, en relación a este tema, un procedimiento parecido al que el propio Reglamento de la Cámara .... ha arbitrado en relación a la iniciativa legislativa extraña a esta Cámara como es la que se inicia por parte de las Comunidades Autónomas. Cuando la iniciativa es ejercida por una Comunidad Autónoma, los representantes de dicha Comunidad tienen un trámite para presentar dicha iniciativa en esta Cámara, "37.

Sin embargo, y también desde el campo doctrinal, no han faltado partidarios de la solución legal. Tal es el caso, por ejemplo, de Santaolalla o de Punset Blanco. Este último, en concreto, ha escrito: «En primer lugar, la iniciativa legislativa es una facultad consistente sólo en la presentación de proposiciones de ley. Lo dice la Constitución misma en el art. 87.3. Ahora bien, es cierto que la presentación de una proposición produce como efecto la puesta en marcha vinculante para la Asamblea del procedimiento legislativo ... Pero, en segundo lugar, esta vinculación no alcanza más que a la fase introductoria de tal procedimiento, que se abre con el ejercicio de la iniciativa y se cierra, en el caso de las proposiciones, con el trámite de la toma en consideración: pretender agotar esa fase en la mera presentación, de modo que las proposiciones válidamente suscritas acudieran directamente a la fase constitutiva o central, no sólo suplantaría la voluntad de la Cámara, que es quien, mediante un Reglamento, ha de articular la tramitación de las proposiciones (art. 89.1), sino que además otorgaría a los órganos o sujetos dotados de iniciativa una potestad legislativa que no les corresponde (art. 66.2) ... Por todo ello, y en tercer lugar, el trámite de la toma en consideración, sobre resultar perfectamente constitucional ... lo es también en cuanto no perjudica de ninguna manera el ejercicio del derecho de iniciativa que la Constitución reconoce, puesto que no condiciona la presentación de proposiciones, sino que se limita a operar como un requisito de procedibilidad de las mismas, libremente apreciada, eso sí, por la Cámaran ${ }^{38}$.

Otros problemas plantea también la tramitación parlamentaria de la iniciativa legislativa popular. Mencionamos los que parecen de más relieve:

Sobre la caducidad de las proposiciones en caso de disolución de las Cámaras establece el artículo 14 de la LOILP: «La iniciativa legislativa popular que estuviera en tramitación en una de las Cámaras, àl disolverse ésta no decaerá, pero podrá retrocederse al trámite que decida la Mesa de la Cámara, sin que sea preciso en ningún caso, presentar nueva certificación acreditativa de haberse reunido el minimo de firmas exigidas.

37. Ibidem.

38. PUNSET BlanCo, R.: "Fase introductoria del procedimiento legislativo" en Revista de Estudios Políticos, n. ${ }^{\circ} 22$ VII-VIII, 1981, p. 216. 
La pregunta que plantea el artículo transcrito es si la no caducidad de la iniciativa legislativa popular se produce sólo en el caso de disolución y no en el supuesto de expiración del mandato parlamentario. El artículo 14 sólo cita la disolución, pero es evidente que debe entenderse que se trata de cualquier supuesto de finalización del mandato parlamentario, y, el único posible, aparte de la disolución -por cualquiera de las causas constitucionalmente previstas- es el de la expiración del mandato por agotamiento del mismo. La solución legal obedece a varias razones, la principal de las cuales sería el fraude que supondría un aplazamiento indefinido, o, al menos exagerado, de la tramitación parlamentaria de la iniciativa para que expire el mandato sin que recaiga decisión final.

Sin embargo la solución del artículo 14 de la Ley Orgánica choca frontalmente -al menos en principio- con el criterio del artículo 207 del Reglamento del Congreso de los Diputados, que establece la caducidad de todos los asuntos pendientes de examen y resolución de la Cámara al disolverse ésta o expirar su mandato. Pero, siguiendo criterio doctrinal generalmente compartido, entre ambas normas no hay relación de jerarquía, sino de competencia. Además, según la profesora Biglino Campos, cuyo criterio puede compartirse, se puede afirmar que «la propia Constitución, al recoger la iniciativa legislativa popular, no remite su regulación al Reglamento, como hace para el caso de la iniciativa del Gobierno y de las Cámaras (art. 87.1), sino que lo hace en favor de una ley orgánica. Estaríamos, por tanto, ante una reserva de reglamento que debe interpretarse de forma elástica, en la medida en que la LOILP intenta sólo introducir algunas modificaciones que derivan de la propia singularidad de las proposiciones de ley de origen popular". Y añade: "Tras realizar este tipo de observaciones podemos inclinarnos por la legitimidad de la disposición de la LOILP que excepciona la caducidad de la proposición de ley popular. Esta afirmación resulta quizá reforzada por el carácter que el Tribunal Constitucional atribuye a la contenida en el artículo 207 del R.C.D. En efecto, la considera dispositiva para la Mesa del Congreso de los Diputados, que puede exceptuarla si lo considera conveniente y así lo permita la naturaleza de la materia sin resolver ${ }^{39}$.

Otro problema de índole temporal se plantea indirectamente al no establecer el artículo 14 de la LOILP plazo alguno entre la recepción de la certificación de la acreditación de firmas por la Junta Electoral Central, y la publicación de la proposición y su inclusión en el orden del día del Pleno, que son, pues, las actividades de impulso de la Mesa en esta fase de la tramitación de la iniciativa popular.

Ninguna solución ofrece la Ley Orgánica y, en definitiva, habrá que esperar el buen criterio de la Presidencia de la Cámara. Porque, no cabe olvidar

39. Biglino CAmpos, P.: "La iniciativa legislativa popular", op. cit., pp. 127-128. La Sentencia del Tribunal Constitucional referida es la 89/1984, de 29 de septiembre. 
que la Mesa ordena la publicación de la proposición, pero no depende de ese órgano de gobierno el que se incluya en el orden del día de un Pleno, cuya fijación corresponde al Presidente, de acuerdo con la Junta de Portavoces (art. 67.1 del Reglamento del Congreso). Ante una injustificada dilación sólo cabe la posibilidad de que se aplique el artículo 68.1 del mismo cuerpo legal, que autoriza la alteración del orden del día del Pleno a petición del Presidente o de dos Grupos Parlamentarios o de la quinta parte de los miembros de la Cámara. Por lo demás, la discrecionalidad vuelve a operar como criterio dominante.

Aunque haya que forzar el contenido de este apartado parece oportuno terminarlo con la mención del artículo 15 de la LOILP, que se refiere a la compensación estatal por los gastos realizados:

"1. El Estado resarcirá a la Comisión Promotora de los gastos realizados en la difusión de la proposición y la recogida de firmas cuando alcance su tramitación parlamentaria.

2. Los gastos deberán ser justificados en forma por la Comisión Promotora. La compensación estatal no excederá, en ningún caso, de treinta millones de pesetas. Esta cantidad será revisada periódicamente por las Cortes Generales".

La Exposición de Motivos de la LOILP - justificando este precepto- afirma que «se establece una compensación estatal por los gastos realizados, siempre y cuando se alcance el número de firmas exigidas para que prospere la iniciativa. Se pretende con ello evitar que resulte oneroso el ejercicio de una forma de participación en la vida pública reconocida en la Constitución".

Para que proceda la compensación pública de los gastos realizados se exigen, como puede verse, dos requisitos: que la proposición alcance su tramitación parlamentaria y que los gastos se justifiquen en forma.

A tenor del artículo 13, la recepción de la notificación de la Junta Electoral Central de haberse reunido el número de firmas exigidas, origina el inicio de la tramitación parlamentaria, pues, como antes se ha señalado, a partir de ese momento la Mesa ha de ordenar preceptivamente la publicación de la proposición. Por tanto, deberá entenderse que será desde esa recepción de la notificación que los miembros de la Comisión Promotora tienen derecho a la compensación económica, siempre y cuando, lógicamente, cumplan el segundo requisito: la justificación de gastos.

Tal justificación de gastos debe realizarse "en forma". Por tal expresión debe entenderse que la Comisión tiene que presentar facturas y recibos correspondientes a los gastos efectuados, sin que se precise intervención notarial alguna.

Respecto a quién debe resarcir $\leadsto E l$ Estado - la conclusión que cabe es que deberán ser cantidades previstas en el Presupuesto de las Cortes, órgano ante el que, en definitiva, se tramita la proposición, y que, además, debe revisarse periódicamente la cuantía de tal resarcimiento. Se supone que el perio- 
do de revisión es el correspondiente a la vigencia del Presupuesto, o sea, anual, aunque la revisión no implique necesariamente aumento de la cantidad de dinero a entregar en concepto de resarcimiento.

La conclusión a la que puede llegarse, no es fruto de una mera especulación teórica. La misma realidad ha acompañado esa especulación. Por una causa o por otra, razones de imitación a modelos extranjeros, desconfianza previa hacia la democracia directa, experiencia propia y reciente en España, etc.., la Constitución de 1978 tiende al recelo hacia la democracia directa y sus instituciones y apuesta decididamente por la democracia representativa, siguiendo, por otra parte, criterio general. Las consecuencias que de ello han derivado para la institución objeto de estudio son evidentes, comportando un, difícilmente superable lastre, que en nada le ha podido prestigiar.

\section{LA PRACTICA DE LA INICIATIVA LEGISLATIVA POPULAR}

Parece oportuno dedicar un capítulo al ejercicio de la iniciativa de la legislativa popular en España. Capítulo breve, pues también parca ha sido la práctica de la misma en nuestro país. Se trata de citar algunos cuantos ejemplos de tal iniciativa como botón de muestra.

Comenzamos nuestra exposición refiriendo un caso anterior a la promulgación de la propia LOILP Una proposición de ley de 1983, fruto de la iniciativa legislativa popular, se destinaba a solicitar el mantenimiento de los Altos Hornos del Mediterráneo en Sagunto. La proposición no fue admitida por la Mesa del Congreso, sin que hubiera recurso ante el Tribunal Constitucional.

Pese a lo que este antecedente pudiera sugerir, hay que aclarar, sin embargo, que el criterio de la Mesa del Congreso ha sido amplio y generoso a la hora de aplicar los criterios materiales de admisión a trámite de las proposiciones populares. La práctica, en este sentido, ha ido mucho más allá en generosidad que la propia regulación de la Ley Orgánica, que no hemos dudado en criticar en anterior capítulo.

Un Acuerdo de la Mesa del Congreso de los Diputados de 27 de julio de 1984 no admitía a trámite una proposición de iniciativa legislativa popular sobre concesión de pensiones de jubilación para administradores familiares, presentada por una Comisión Promotora de catorce personas, integrantes varias de ellas del SANAF (Sindicato Autónomo Nacional de Administradores Familiares). La proposición de ley pretendía que los medios para la pensión de administrador familiar se obtuvieran de recaudar mil pesetas a pagar obligatoriamente por todas las familias españolas. La Mesa entendió que tal iniciativa contenía una norma tributaria, no susceptible, por tanto, de iniciativa popular. La Comisión Promotora recurrió en amparo ante el Tribunal Constitucional, quien en Auto 26/1985, de 16 de enero, entendió correcta la actuación de la Mesa del Congreso al calificar como de naturaleza tributaria la pro- 
posición de ley «en méritos de la cual se impone a cada familia residente en territorio español el pago de lo que se denomina ahorro familiar mensual por un importe de 1000 pesetas".

Poco más tarde -marzo de 1985- se volvería a presentar una iniciativa popular ante la Mesa del Congreso, pero dando carácter voluntario a la prestación pecuniaria antes citada. La Mesa volvió a negar la admisión a trámite de la proposición, por entender que seguía afectando a materia tributaria, y tener contenido sustancialmente equivalente a la anterior.

El Tribunal Constitucional, a quien se había acudido otra vez en amparo, por Auto 592/1985, de 18 de septiembre, entendió que la supresión del sentido obligatorio de las prestaciones pecuniarias "no altera, por sí sola, la esencial dimensión tributaria de la iniciativa que ha tratado de ejercerse nuevamenten. Además, el Tribunal entendía válida también como causa de no admisión el hecho de que la iniciativa reproducía esencialmente la anterior presentada en la misma legislatura. Durante la legislatura siguiente -1990- volvería a presentarse otra iniciativa de similar contenido, que tampoco la Mesa del Congreso admitió a trámite.

Tampoco admitiría la Mesa del Congreso otra proposición, fruto de la iniciativa popular, presentada durante la cuarta legislatura - 1992- sobre el ejercicio, disfrute y comercialización de obras de arte.

Sin embargo, la causa más habitual de que no haya prosperado la iniciativa popular con más frecuencia es la caducidad -el transcurso de seis meses, prorrogables otros tres más, artículo 7.3 LOILP- producida por la falta de recogida de firmas suficientes. Tales fueron, entre otros, los casos de una proposición de 1987 sobre la responsabilidad de las Administraciones Públicas en cuestiones relacionadas con los centros de enseñanza; de otra sobre la reparación de daños producidos por el síndrome tóxico, que se presentó en 1989 y se trasladó a la cuarta legislatura, y de las presentadas en 1990 sobre la jornada de médicos titulares, la abolición del trabajo precario, y el abandono de la energía nuclear.

Por último cabe señalar que se retiró, por la propia Comisión Promotora, una proposición sobre regulación del fomento del cese anticipado de la actividad agraria.

En sentido contrario, cabe destacar la aprobación de la primera ley cuyo origen está en la iniciativa popular. Se trata de la Ley de propiedad horizontal núm. 8/1999, de 6 de abril, BOE del 8 de abril. Su contenido reforma una Ley sobre la misma materia, promulgada en 1960.

En su Exposición de Motivos se dice que la finalidad del nuevo texto legal es la de recoger las "aspiraciones de la sociedad en materia de regulación de la propiedad horizontal. Aspiraciones nuevas que se concretan, sobre todo, en lo referente a la flexibilización del régimen de mayorías para tomar determinados acuerdos, en la lucha contra la morosidad de determinados copropietarios y en la reforma de la regulación de los órganos de las comunidades. Con ello la normativa sobre la materia, sigue la Exposición de Motivos, "gana 
en flexibilidad y dinamismo, pero también en eficacia, y se acomoda a los nuevos requerimientos sociales".

El examen de la práctica de la iniciativa legislativa popular reafirma lo dicho en anteriores capítulos. Hoy por hoy, no es figura que haya arraigado en nuestro país y su práctica ha sido, como puede apreciarse, mínima. Los motivos pueden ser de diversa naturaleza: desde el desinterés generalizado por la cosa pública, excepto quizá en su aspecto económico -y las materias tributarias están excluidas de la iniciativa popular- hasta las propias trabas de procedimiento impuestas por la Constitución y la LOILP, así como la necesidad de reunir las quinientas mil firmas, cantidad muy notable, cuya dificultad de cumplimiento ha podido producir los casos de caducidad antes descritos.

Las propias restricciones materiales al objeto de la iniciativa popular han dificultado, en buena medida, su utilización. El profesor Chofre Sirvent critica, por ejemplo, la exclusión de la materia relativa a derechos fundamentales y libertades públicas, "ya que ésta constituye uno de los ámbitos más idóneos para la participación directa o semidirecta de los ciudadanos, sin perjuicio del sistema representativo, que es el que prevalece. En esta materia, debido a la ambigüedad con que el legislador constituyente ha diseñado el artículo 81.1, hay supuestos que son susceptibles de no ser aprobados por ley orgánica $y$, por tanto, ello da lugar a que la iniciativa legislativa popular pueda ser una vía válida para regular las mismas $" 40$.

Toda esta situación es, por otra parte, fiel trasunto de la primacía otorgada por nuestra Constitución a la democracia representativa frente a la democracia directa. Primacía extensamente referida en los primeros capítulos de este trabajo, a los que ahora habría que remitirse, y que ha inmovilizado, prácticamente, las considerables posibilidades de la institución objeto de nuestro estudio.

\section{LA INICIATIVA LEGISLATIVA POPULAR EN LAS COMUNIDADES AUTONOMAS}

\section{Aspectos generales}

La figura de la iniciativa legislativa popular ha sido recogida e institucionalizada por todos los Estatutos de Autonomía, con la sola excepción del de Castilla y León. En desarrollo de esos preceptos estatutarios se han ido aprobando diversas leyes autonómicas de iniciativa legislativa popular, excepto en la Región citada.

No es objeto directo de este trabajo entrar en los detalles pormenorizados de la iniciativa popular en todas y cada una de las Comunidades Autónomas,

40. ChOFRE SiRvent, J.F.: Significado y función de las leyes orgánicas, Tecnos, Madrid, 1994, p. 277. 
sino que su objeto es la iniciativa legislativa popular en el ámbito nacional. Sin embargo, cabe hacer, siquiera, una referencia a los aspectos más significativos de su regulación autonómica. Para ello, puede seguirse una sistemática paralela a la empleada en el caso de la institución a nivel nacional.

Llama la atención, de entrada, los títulos que reciben las diversas leyes de desarrollo de la institución en algunas Comunidades Autónomas: "de iniciativa legislativa popular o iniciativa popular, en el caso del País Vasco, Galicia, Cantabria, La Rioja, Aragón, Canarias, Navarra, Extremadura y Baleares. En Andalucía, Asturias, Murcia, Castilla-La Mancha y Madrid se añade al título del texto legal la "iniciativa legislativa de los Ayuntamientos", y en el caso murciano "de las comarcas".

Cronológicamente, la primera Comunidad Autónoma en regular la iniciativa legislativa popular, en su ámbito propio, fue el Principado de Asturias. Lo hizo por la Ley 4/1984, de 5 de junio, "reguladora de la iniciativa legislativa de los Ayuntamientos y de la iniciativa popular , publicada en el Boletín Oficial del Principado de Asturias, número 133, de 8 de junio de 1984.

En su Exposición de Motivos, la Ley justifica la urgencia en cumplir el mandato del artículo 31.1 del Estatuto de Autonomía para Asturias, "dado que una de las características definitorias y configuradoras del Principado de Asturias en su carácter de Comunidad Autónoma uniprovincial en la que los Ayuntamientos deben tener legalmente garantizado su derecho a intervenir en la adopción de las decisiones que legalmente les afecten".

Cabe hacer notar, en todo caso, que la Ley asturiana se promulgó antes de que transcurrieran tres meses de vigencia de la LOILP

En Cataluña, la iniciativa legislativa popular se desarrolló mediante la Ley 2/1995, de 23 de marzo. Consta de 15 artículos, dos Disposiciones Transitorias y dos Disposiciones Finales. Fue la última de las leyes reguladoras de esta materia.

Característica común a la legislación autonómica, en la materia que nos ocupa, es que las exposiciones de motivos de las leyes de desarrollo invocan los correspondientes mandatos estatutarios y los artículos 87.3, 9.2 y 23 de la Constitución española (alegados cuantitativamente por el orden reseñado). Son excepción los Estatutos de Galicia y País Vasco-que no se refieren a la Constitución en la correspondiente exposición de motivos, sino sólo a sus Estatutos- y Canarias, en donde no se invoca precepto alguno.

En 1984 se promulgaron las leyes correspondientes a Asturias, Murcia y Aragón. En 1985, las de La Rioja, Cantabria, Castilla- La Mancha y Extremadura. Aparecen en 1986 las leyes correspondientes a Canarias, Madrid y País Vasco. En 1988 las de Andalucía y Galicia. Las Islas Baleares y la Comunidad Valenciana desarrollaron la iniciativa legislativa popular autonómica por sendas leyes de 1991 y 1993 , respectivamente.

En el caso de la Comunidad Foral de Navarra, hay que distinguir la Ley reguladora de la iniciativa legislativa popular (Ley foral 3/1985, de 25 de marzo) de la Ley reguladora de la iniciativa legislativa de los Ayuntamientos de Navarra (Ley foral 4/1985, también de 25 de marzo). 
Las características de las leyes autonómicas de desarrollo son relativamente similares en cuanto a su contenido, como luego se examinará, sin que tampoco haya excesivas diferencias formales. Su extensión varía entre los 22 artículos de la Ley murciana, seguida de los 20 de Andalucía y Valencia, hasta los 11 de Cantabria, siendo lo más habitual la aproximación a ese último número de artículos.

\section{Titulares de la iniciativa}

Respecto a los requisitos subjetivos -titularidad- para el ejercicio de la iniciativa legislativa popular en las Comunidades Autónomas, podrían establecerse los siguientes rasgos generales: poseer la vecindad autonómica -ciudadanía autonómica en expresión de muchos autores ${ }^{41}$ - o sea la vecindad administrativa, es decir, estar empadronado en un municipio de la Comunidad Autónoma, independientemente del lugar de nacimiento o del lugar de residencia de hecho. Dicha ciudadanía autonómica o vecindad administrativa se acredita con la inscripción en el correspondiente censo electoral, con la consiguiente exigencia de la mayoría de edad. En expresión del profesor Rallo Lombarte, "deberían ejercer la iniciativa legislativa popular aquellos ciudadanos que reuniesen los requisitos para el ejercicio del derecho de sufragio (mayoría de edad, inscripción en el censo electoral vigente y no estar comprendido en los supuestos del art. 3 LO 5/1985 -sentencia judicial firme con privación de derecho de sufragio, declaración de incapacidad por sentencia judicial firme que lo exprese, internamiento psiquiátrico con declaración expresa-)” 42.

El número de firmas requeridas para presentar al Parlamento autonómico la proposición de ley de iniciativa legislativa popular oscila en función del número de habitantes de cada Comunidad Autónoma. Así, se exigen un mínimo de 75.000 en Andalucía, 30.000 en el País Vasco, 6.000 en La Rioja, 7.000 en Navarra, etc.

Como peculiaridad puede citarse el artículo 2 b) de la Ley $9 / 1984$, de 22 de noviembre, de la Región de Murcia, reguladora de la iniciativa legislativa popular y de los Ayuntamientos y Comarcas (BOMU, número 281, de 10 de diciembre de 1984), que atribuye -en aplicación literal del artículo 30.1 de su Estatuto de Autonomía - la titularidad de la iniciativa legislativa a "uno o varios Municipios o una o varias comarcas, cuya población conjunta represente como minimo un censo de 10.000 babitantes.

41. RAllo LOMBARTE, A.: La iniciativa legislativa en el derecho autonómico, Universitat Jaume I, Castellón, 1993, p. 275.

42. Ibidem, p. 276. 


\section{OBJETO DE LA INICIATIVA}

Respecto a las materias sobre las que puede versar la iniciativa legislativa popular autonómica puede apreciarse que, lógicamente, existe una traslación de los límites contenidos en la LOILP (artículo 2), o sea: las materias propias de leyes orgánicas, las de naturaleza tributaria, carácter internacional, las relativas a la prerrogativa de gracia y las mencionadas en los artículos 131 y 134.1 del Texto Constitucional.

Al igual que ocurre en la Constitución, las materias de naturaleza tributaria o la elaboración del presupuesto son de iniciativa exclusivamente gubernamental en el ámbito autonómico. Respecto a la prerrogativa de gracia o a las materias de carácter internacional son irrelevantes en el campo de las Comunidades Autónomas.

Teniendo en cuenta que no cabe potestad legislativa orgánica autonómica de ningún tipo, la profesora Biglino Campos entiende que tal limitación por razón de la materia -la propia de leyes orgánicas- podría trasladarse, en las Comunidades Autónomas, a leyes autonómicas con significación paralela a las leyes orgánicas respecto a la Constitución, es decir, las que supusieran un desarrollo directo de los Estatutos ${ }^{43}$.

En otro sentido, el profesor Rallo Lombarte discrepa de la traslación del artículo 2 de la LOILP al ámbito autonómico, dado que, el hacerlo, puede suponer una limitación material al ejercicio de la iniciativa legislativa popular en ese ámbito. Considera como irrelevante dicho traslado por estar vacío de consecuencias prácticas y suponerlo «atentatorio a la autonomía política reconocida por la Constitución a las Comunidades Autónomas". Añade el citado profesor que tan sólo podría pensarse en la cabida de un cierto derecho de traslado en el caso de la planificación, por ley, de la actividad económica general. Y en este caso, la exclusión de la iniciativa legislativa popular se produciría por «la complejidad de una materia que parece debe reservarse, de iure $o$ de facto, a la iniciativa gubernamental, pero no en la necesaria exclusión de las materias del art. 2 de la LO 3/1984,"44.

Respecto a los limites materiales a la iniciativa legislativa popular previstos por las correspondientes leyes autonómicas podemos citar como más habituales o comunes los siguientes:

a) Las competencias de la propia Comunidad Autónoma. Evidentemente, la iniciativa popular autonómica no puede versar sobre materias sobre las que la propia Comunidad no tenga competencias. Pese a ello, algún sector doctrinal -el malogrado profesor Ribas Maura, entre otros- admite la posibilidad de ampliar

43. Biglino Campos, P.: "La iniciativa legislativa popular en los ordenamientos jurídicos regionales" en Revista de Estudios Políticos n. ${ }^{\circ} 46-47,1985$, p. 304.

44. RAllo LOMBarTe, A.:La iniciativa legislativa en el derecbo autonómico, op. ci.,p.277 
las competencias de la Comunidad autónoma en virtud de la iniciativa popular.

b) La organización y régimen jurídico de las instituciones de la Comunidad Autónoma.

c) El desarrollo básico del Estatuto.

d) Las materias cuya legislación requiera, para ser aprobada, de mayorías cualificadas.

e) Las cuestiones relacionadas con la distribución territorial interna de la Comunidad.

f) El procedimiento legislativo.

Se trata de una enumeración de carácter indicativo, no exhaustivo. En efecto, estas materias citadas no son recogidas por todas las Comunidades $y$, a su vez, incluyen otras que aquí no se han referido. Ciertamente, son casi todas las leyes autonómicas que, de una u otra forma, citan como excluidas de la iniciativa legislativa popular las del artículo 2 de la Ley Orgánica estatal.

\section{PRocedimiento y PECUlLARIDADES}

No vale la pena detenerse a analizar los requisitos formales y las fases de procedimiento que las diversas Comunidades Autónomas exigen para ejercer la iniciativa legislativa popular, en donde, y salvo excepciones, late un cierto criterio traslaticio de la LOILP Pese a ello, sí que vale la pena examinar, siquiera sea brevemente, el ejercicio de la posibilidad de la interposición del recurso de amparo ante el Tribunal Constitucional una vez que la Mesa del Parlamento autonómico declare la inadmisibilidad de una proposición de ley de iniciativa popular en aplicación de los criterios legales. La mayor parte de las leyes autonómicas de desarrollo de la iniciativa popular también recuerdan la posibilidad de interponer dicho recurso de amparo.

La crítica que algunos autores han realizado a la posibilidad de este tipo de amparo ante el Tribunal Constitucional, por la inadmisión de una proposición de ley de origen popular a nivel estatal, se han acrecentado al admitirse también el recurso en la iniciativa autonómica. Sin embargo, en el fondo, con esa crítica se olvida el hecho de que la actitud denegatoria de la Mesa Parlamentaria puede conculcar directamente el derecho de participación directa previsto en el artículo 23 de la Constitución, y no se trata, en absoluto, de ún recurso forzado. Otros autores, defensores de la solución legal, defienden la procedencia del recurso de amparo por la especial naturaleza del órgano que cercena el derecho de ejercer la iniciativa ${ }^{45}$.

A continuación, se hace referencia, a título de ejemplo, a algunos de los recursos de amparo interpuestos ante el Tribunal Constitucional por la inad-

45. García Martínez, M.A.: «La iniciativa legislativa popular y su vigencia en el Estado contemporáneo" en Revista de la Facultad de Derecho de la Universidad Complutense, n. ${ }^{\circ}$ 74, 1988, p. 233. 
misión, por parte de Mesas parlamentarias autonómicas, de iniciativas legislativas populares.

La Mesa de las Cortes de Castilla-La Mancha acordó la no admisión a trámite de una iniciativa legislativa popular, que, a tenor de lo previsto en el artículo 12 del correspondiente Estatuto de Autonomía, presentó una "proposición de ley por la que se declara el Rincón de Anchuras como Parque Natural», ante la amenaza de dicha zona natural por el proyecto del Ejército del Aire de instalar un campo de tiro. La Mesa no admitió a trámite la proposición, al entender que escapaba de las competencias regionales un asunto relacionado con la Defensa Nacional. Los recurrentes ante el Tribunal Constitucional entendian que su proposición, no sólo no se hallaba entre las materias excluidas por el artículo 87.3 de la Constitución, sino que se destinaba a la protección del medio ambiente, citando el artículo 148.1 .9 de la Constitución, el Estatuto Autonómico y el Real Decreto 1676/1984, por el que su Comunidad asumía competencias en lo referente a la declaración de Parques Naturales.

El Tribunal Constitucional, por Auto 428/89, de 21 de julio, no admitió el recurso de amparo, dando pues, la razón a la Mesa de las Cortes castellanomanchegas, porque aun reconociendo la competencia autonómica en la declaración de parques naturales, la misma no podía efectuarse respecto de una zona declarada por el Gobierno de la Nación como de interés para la Defensa Nacional, "en ejercicio legítimo de una competencia estatal".

El Tribunal Constitucional tampoco admitió -Auto 570/89, de 27 de noviembre- el recurso de amparo presentado contra la no admisión de una proposición de ley de iniciativa popular por parte de la Mesa de las Cortes castellano-manchegas, por la que el Ayuntamiento de Toledo pretendía crear un fondo regional de cooperación municipal. La Mesa argumentó su rechazo por el hecho de que la proposición contenía normas de carácter presupuestario.

El Tribunal Constitucional fundamentó su inadmisión en la extemporaneidad del recurso y en que la norma violada presuntamente se refería a la garantía de la autonomía municipal, que no configurà un derecho fundamental cuya transgresión deba repararse por la vía del recurso de amparo. No parece tan fundamentado este segundo motivo, pues, si es verdad que, por aquel entonces, la autonomía municipal se excluía de la tutela de la jurisdicción constitucional, el amparo se solicitaba porque la inadmisión de la iniciativa del Ayuntamiento de Toledo podía conculcar el derecho fundamental de petición. En todo caso, podría haberse planteado el Tribunal si era el Ayuntamiento, como tal, el titular de la iniciativa, y su posible legitimación para ejercerla. El motivo alegado por la Mesa de las Cortes autonómicas parece mucho más sólido.

Otra Sentencia del Tribunal Constitucional -ya citada anteriormenteresolvió un recurso de amparo interpuesto contra un acuerdo de la Mesa de un Parlamento autonómico denegatorio de proposición de iniciativa legislativa popular. Se trata de la Sentencia 76/1994, de 14 de marzo, denegando el amparo solicitado contra un Acuerdo de la Mesa del Parlamento Vasco por la 
que se declaraba la inadmisibilidad de una proposición de ley de iniciativa legislativa popular por la que se pedía al Parlamento Vasco que instara ante las Cortes Generales una reforma de la Constitución, concretamente la disposición adicional segunda, en el sentido de poder acceder a la autodeterminación los territorios forales. Los recurrentes acudian en amparo ante el Tribunal Constitucional por entender que la Ley vasca 8/1986, reguladora de la iniciativa legislativa popular, era inconstitucional precisamente en aquellos artículos en los que se había basado el acuerdo de inadmisibilidad de la Mesa del Parlamento de Vitoria, muy especialmente el artículo 2.e que impide que la proposición popular verse sobre la iniciativa y procedimiento legislativo, lo que vulnera -siempre según los recurrentes- el principio de soberanía popular y el derecho a la participación en los asuntos públicos. Entendían, además, que el objeto de su proposición no figuraba entre las materias excluidas de iniciativa popular de los artículos 87.3 y 2 de la Constitución y de la LOILP, respectivamente (Antecedente 3.a).2).

El Tribunal Constitucional entendió que "sin necesidad de entrar ahora en consideraciones que no vienen al caso acerca del contenido y alcance jurídicos del principio de soberanía, sí resulta necesario poner de manifiesto de entrada que el derecho a participar directamente en los asuntos públicos, como todos los derechos que la Constitución establece, no puede sino ejercerse en la forma jurídicamente prevista en cada caso ... Establecido, pues, que los derechos de participación directa sólo tienen el alcance que deriva del ordenamiento vigente, debe aceptarse igualmente que, en nuestro caso, el hecho de que ese ordenamiento excluya determinadas materias de la iniciativa legislativa popular no vulnera ningún principio ni regla constitucional». (fto. jco. 3).

Advierte el Tribunal, en ese mismo fundamento jurídico, que no cabe oponer reparo alguno a que la Ley autonómica reguladora de la iniciativa legislativa popular excluya de dicha iniciativa determinadas materias, al igual que, en el ámbito estatal, hacen los artículos 87.3 de la Constitución y la LOILP que lo desarrolla. "También en la Comunidad Autónoma del País Vasco el pueblo no tiene más derechos de participación política que los que le reconoce el ordenamiento vigente y en la forma de gobierno establecida en la Comunidad Autónoma priman también los mecanismos de democracia representativa" (ibidem).

Según el fundamento jurídico siguiente la causa de inadmisibilidad prevista en la Ley vasca ha de interpretarse en el sentido de que la iniciativa popular no puede tener como objeto el régimen regulador de toda iniciativa -popular, gubernamental o parlamentaria- y el procedimiento legislativo, porque supondría la posibilidad de modificar el propio Estatuto de Autonomía -que es quien regula ese régimen- que por ser materia reservada a ley orgánica queda excluida de la iniciativa legislativa popular a tenor del propio artículo 87.3 de la Constitución.

La defensa frente a la inadmisión de la Mesa del Parlamento autonómico tiene en Aragón y Canarias sendas peculiaridades que conviene, siquiera, citar 
de paso. En el primer caso, la Comisión Promotora puede acudir al Justicia de Aragón, pero no puede tramitarse la queja si antes se ha acudido al recurso de amparo. Por lo demás, hay que recordar que las resoluciones del Justicia -como las del Defensor del Pueblo- no pasan de ser advertencias, recomendaciones o meras sugerencias, sin facultad coercitiva alguna.

En el caso canario, contra la inadmisión por la Mesa cabe recurso de queja ante el Pleno de la Cámara autonómica, a tenor del artículo 5 de la Ley de Iniciativa Legislativa Popular de Canarias.

Requisito común a todos los ordenamientos autonómicos es la necesidad de la toma en consideración, fruto del mimetismo con la regulación estatal en esta materia. Necesidad que, si en la regulación estatal motivó críticas, no han sido menores en el ámbito autonómico.

Por otro lado, y a diferencia del ordenamiento estatal, las leyes de iniciativa legislativa popular de Galicia, Aragón, Baleares y Canarias posibilitan la presencia de un miembro de la Comisión Promotora de la iniciativa en el trámite de la toma en consideración ante el Pleno.

También dentro del ámbito autonómico no es muy difícil prever un parco ejercicio de la iniciativa popular, con lo que se habrá perdido una buena ocasión para favorecer la participación política de los ciudadanos. 
de paso. En el primer caso, la Comisión Promotora puede acudir al Justicia de Aragón, pero no puede tramitarse la queja si antes se ha acudido al recurso de amparo. Por lo demás, hay que recordar que las resoluciones del Justicia -como las del Defensor del Pueblo- no pasan de ser advertencias, recomendaciones o meras sugerencias, sin facultad coercitiva alguna.

En el caso canario, contra la inadmisión por la Mesa cabe recurso de queja ante el Pleno de la Cámara autonómica, a tenor del artículo 5 de la Ley de Iniciativa Legislativa Popular de Canarias.

Requisito común a todos los ordenamientos autonómicos es la necesidad de la toma en consideración, fruto del mimetismo con la regulación estatal en esta materia. Necesidad que, si en la regulación estatal motivó críticas, no han sido menores en el ámbito autonómico.

Por otro lado, y a diferencia del ordenamiento estatal, las leyes de iniciativa legislativa popular de Galicia, Aragón, Baleares y Canarias posibilitan la presencia de un miembro de la Comisión Promotora de la iniciativa en el trámite de la toma en consideración ante el Pleno.

También dentro del ámbito autonómico no es muy difícil prever un parco ejercicio de la iniciativa popular, con lo que se habrá perdido una buena ocasión para favorecer la participación política de los ciudadanos. 